\title{
Analysis of Heat Transfer Rate for Different Annulus Shape Properties-Enhanced Beeswax-Based Phase Change Material for Thermal Energy Storage
}

\author{
Durgesh Kumar Mishra, Sumit Bhowmik, and Krishna Murari Pandey \\ Department of Mechanical Engineering, National Institute of Technology Silchar, Silchar 788010, Assam, India \\ Correspondence should be addressed to Krishna Murari Pandey; kmpandey2001@yahoo.com
}

Received 11 September 2021; Revised 19 January 2022; Accepted 29 January 2022; Published 27 February 2022

Academic Editor: Wang Hui

Copyright ( $\odot 2022$ Durgesh Kumar Mishra et al. This is an open access article distributed under the Creative Commons Attribution License, which permits unrestricted use, distribution, and reproduction in any medium, provided the original work is properly cited.

\begin{abstract}
Thermal exploration of melting phenomena of four different annulus shapes' (circular-circular, circular-rectangular, rectangularcircular, and rectangular-rectangular) beeswax-based phase change material for latent heat energy storage system is discussed here. To overcome the low efficiency in heat transfer because of low thermal conductivity of beeswax (the energy storage material in the current study), the composite-beeswax approach has been investigated numerically. Three metal oxides $\left(\mathrm{Al}_{2} \mathrm{O}_{3}, \mathrm{MgO}\right.$, and $\mathrm{SiO}_{2}$ ) with different volume concentrations $(1 \%, 3 \%$, and $5 \%)$ containing high thermal conductivity are dispersed into the pure beeswax. The 2-d continuity and momentum as well as energy transport mathematical model inside the composite-beeswax system have been adopted for the study, and we validated the model by available results in the literature. The obtained results revealed that both the melting rate and heat transfer are improved slightly in the case of rectangular-rectangular annulus shape. It was also shown from the result that the melting rate and heat transfer are improved significantly with the presence of metal oxide particles. Moreover, it was obtained that the types of particles have not affected noticeably the melting rate and heat transfer. For the three investigated nanoparticles, temperature of the system attained $346.4 \mathrm{~K}$ at $15000 \mathrm{~s}$ of process; at the same time, it is $341 \mathrm{~K}$ as noted for the beeswax, which shows an improvement of $1.4 \%$ in the case of circular-circular annulus and $\mathrm{Al}_{2} \mathrm{O}_{3}$. In the same conditions, melt fraction increases from 0.58 for beeswax to 0.91 for composite unit, thus showing $56.8 \%$ of improvement in the melting rate.
\end{abstract}

\section{Introduction}

Energy is the backbone of the whole world because all the necessities of a society are fulfilled by it. As the population of the society is increasing drastically, the demand of energy is also increasing in the same manner and that leads to a gap between energy supply and demand chain [1]. The utilization of available renewable energy source such as solar energy may reduce this mismatch. Since some of the energy (like solar energy) only exists in daytime, that is why it is becoming progressively challenging to overlook the gap [2]. Since solar energy is not available all the time, that is, only available in the day, the application efficiency is low. In this regard, energy storage system is a significant section that plays a crucial role in the application efficiency enhancement of the solar thermal energy system [3-5]. Nowadays, for universal population and pollution issue, latent heat energy storage has gained a larger attention in the viewpoint of energy storage and utilization. The main advantages of latent heat storage system are that it can absorb energy without further temperature increment and at the same time it can contain high energy storage density. Phase change material (PCM) is a kind of material that works in the principle of heat energy storage in the form of sensible and latent heat. In both absorbing capabilities, latent heat is more useable because of negligible temperature variation. PCM works in cyclic manner first charging and then discharging. In solidliquid kind of PCM, heat is absorbed during charging and melts. In this process, PCM gains melting latent heat. For the discharging case or solidification process, heat is released 
when the surrounding temperature was lesser than solidification temperature of PCM [6,7]. PCM is classified normally into three fashions: first is organic, second is inorganic, and third one is the combination of organic and inorganic or called eutectic [8]. Among all the three, organic PCM got great devotion because of the appropriate phase alteration temperature, congruent melting, good amount of heat absorbing capacity, low vapour pressure, no supercooling, nontoxicity, no volume alteration during phase change, and excellent chemical and thermal stability [9]. At the same time, organic PCMs contain less thermal conductivity which is approximately $0.1-0.35 \mathrm{~W} / \mathrm{m}-\mathrm{K}$, which confines their applications. Organic PCMs are utilized in various engineering applications like the solar system, building energy management, Li-ion battery, spacecraft, packaging, etc. [10-15]. Organic kind of PCM is subdivided into two categories, paraffin and nonparaffin. Paraffin is a by-product of petroleum and it is a limited resource. So, it is the responsibility of the researcher to explore the natural kind of nonparaffin PCM [16]. In this regard, beeswax (BW) can fill the gap if paraffin wax (PW) will be unavailable in the future. In the midst of all PCMs reconnoitred, BW can be a desirable selection to be employed as the PCMs due to its large amount of heat-storing capacity, being environmentally friendly, having a cheap price, and being nonflammable and nontoxic. BW is the outcome of the metabolic practice of bees where wax is excreted from the abdominal parts of bees. BW consists of hydroxypalmitate, palmitoleate, palmitate, and oleate esters with long-chain aliphatic alcohols, which is classified as organic nonparaffin PCM with chemical formula $\mathrm{C}_{15} \mathrm{H}_{31} \mathrm{COOC}_{30} \mathrm{H}_{61}$. But, BW has a less thermal conductivity and medium range melting temperature, which limits the array of applications. At the same time, leakage during phase change process will also hamper the application BW $[17,18]$. To eliminate the huddle of less thermal conductivity, several methods have been adopted for improving rate of heat transfer and speeding up the meltfreeze cycle. There are mainly two approaches to improve thermal conductivity, either disperse the high thermal conductivity particles into melted PCM $[19,20]$ or impregnate the melted PCM into high conductivity porous or foam structure [21, 22]. Iasiello et al. [23] employed metallic foam made up with net-like structure that connected with high conductivity metallic ligaments that produce pores, which is helpful for conductivity increment and leakage prevention of PCM. Ghahremannezhad et al. [24] incorporated highly porous, large surface area and high thermal conductivity metal foam that makes a good candidate for various PCM integrated thermal system. References [25, 26] studied PCM coupled with finned metal foam. Metal foam integrated fin enhanced the heat transfer performance of PCM. The incorporation of properties-enhancing material not only raised the cost and weight of the energy storage units, but also reduced the PCM volume, which is the matrix material of energy storage system $[27,28]$. Recently, various innovative experimental and numerical analyses on thermal performance of various PCMs are tried with the combination of various nanoparticles. But, accurate nanoparticle selection also affects the heat transfer efficiency in a great manner. For the numerical analysis, ANSYA fluent software has been adopted to solve thermal performance of heat transfer problem by solving collectively continuity, momentum, and energy equation for various composite PCM. Tasnim et al. [28] investigated porous metal foam impregnated composite PCM analytically which is enclosed in a rectangular box. Darcy model was used to solve the current problem after assuming that PCMs act as single phase nanofluid for metal foam. Phase alteration process starts by the heat transfer initially through the conduction and after melting by convection. Sebti et al. [29] investigated by enthalpy-porosity method of composite PCM in 2D square cavity. They stated that, after incorporation and increment of nanoparticles inside the PCM, the rate of heat transfer also increases; this is because of the thermal conductivity increment. However, viscosity escalation is leading to the reduction of the velocity of melted PCM. Zarma et al. [30] investigated the performance of nanoparticle-PCM incorporated with concentrator photovoltaic system. Complete performance of the hybrid system under different nanoparticles $\left(\mathrm{Al}_{2} \mathrm{O}_{3}, \mathrm{CuO}\right.$, and $\left.\mathrm{SiO}_{2}\right)$ concentration into the PCM is discovered. Results revealed that, by adding $\mathrm{Al} 2 \mathrm{O} 3$, the thermal conductivity of PCM has considerably increased, when compared with two other nanoparticles. Cheng et al. [31] prepared BW/tetradecanol/carbon fiber/expanded perlite (EP) composite PCM for the storage of heat energy. Thermal conductivity of the composite enriched from 0.24 to $1.245 \mathrm{~W} / \mathrm{m}-\mathrm{K}$ which could form efficient charge-discharge cycle. The porous EP structure could prevent leakage during the molten state with the help of surface tension force. During the development of BW as PCM, Putra et al. [32] explored the BW/CNT composites for thermal energy storage. They tried to examine the two main hampers of PCM, less thermal conductivity, and volume decrement at the time of phase conversion. Results disclosed that the thermal conductivity of the composite PCM was enriched by $132 \%$. Putra et al. [33] inspected the character of $\mathrm{BW}$ and $\mathrm{CuO}$ as composite PCM. Five samples have been prepared and characterized. During the characterizations, it was found that the melting temperature of samples reduced slightly at the same time heat storage capacity also reduced, but caused no significant effects on the performance of composite. Moreover, utilization of nanoparticle enhanced properties PCM allows attaining a higher thermal regularity and electrical efficiency for the system. However, various researchers tried to analyse the behaviour of metaloxide particles and found less effect on the outcomes $[34,35]$. Thus, the nanooxides incorporation is still under argument with the PCM incorporation.

Ghalambaz et al. [36] explained the melt behaviour and heat transfer rate of PCM. The PCM was electrically conductive, enclosed in a square container exposed in nonuniform magnetic field. Magnetic field location and magnitude do not reveal the significant effect over natural convection during starts of melting. In time the melt fraction advancement takes place, the melt fraction value increases which enhances the fluid velocity and the magnetic field effect boosts. 
In Ghalambaz and Zhang [37], the conjugate flow and heat transfer of phase change materials (PCMs)-metal foam confined between two annuli is addressed. The results are compared with theoretical and experimental studies available in the literature and found in good agreement. The steady-state solution and transient characteristics are addressed. The results demonstrate that the heat sink filled with PCM-metal foam can enhance the heat transfer at the hot surface, particularly at low external cooling power (Biot number $<0.2$ ). The results reveal that the fusion temperature of phase change material is the key parameter on temperature controlling of the hot surface. Using the phase change heat sink results in a cooling power four times higher than that of pure external convection during the pulse load.

In Ho et al.'s [38] experimental study, nanoencapsulated phase change material (NEPCM) nanoparticles with particle sizes in the range of $250-350 \mathrm{~nm}$ are synthesized. The impact of the nanoparticle's concentration, the heating power, and the flow rate is investigated on the channel wall temperature, Nusselt number, convection ratio, performance index, and coefficient of performance. The results show that the presence of NECPM particles improves heat transfer and the index of performance up to $70 \%$ and $45 \%$, respectively. The observed enhancement of heat transfer is particularly notable at low Reynolds numbers. However, at the high Reynolds numbers, the presence of NECPM particles may reduce the convection ratio and performance index, which is mainly due to the increase of the viscosity and reduction of the sensible heat of the working fluid in the presence of NEPCM nanoparticles.

The current article aims to perform numerical investigation on three commercial metal oxides-based composite PCM samples with three different volume concentrations of nanoparticles in four different annulus shapes' nano-PCM container to evaluate their thermal performance. The first objective is to establish a melting process's mathematical model for PCM through ANSYS Fluent and validate it from experimental results available in literature. The second objective is to perform a comparative study to analyse the thermal behaviour of the various annulus shape energy storage unit filled with BW. The last objective is to conduct a comprehensive approach of various energy storage systems containing dispersed nanoparticle $\left(\mathrm{Al}_{2} \mathrm{O}_{3}, \mathrm{MgO}\right.$, and $\left.\mathrm{SiO}_{2}\right)$. For estimating the complete performance of the unit, temporal evolutions of the average composite PCM liquid fraction and temperature have been calculated for the various investigated cases. The motivation for the current work is to gather our knowledge about the new kind of energy storage system that may be utilized for various heat exchanger units, food safety containers, battery thermal management, etc.

\section{Physical and Computational Model}

Beeswax is selected as thermal energy storage material and air is utilized as a heat transfer fluid (HTF). The latent heat energy storage system used in the current study is four different annulus shapes with internal and external geometry: (1) rectangular-rectangular (rec-rec), (2) rectangular- circular (rec-cir), (3) circular-circular (cir-cir), and (4) circular-rectangular (cir-rec). The surface areas of all the annuli ar equal, where air flows over the outer side with temperature $340 \mathrm{~K}$ and at the same time over the inner side of the annulus exposed to a heat flux of $363 \mathrm{~W} / \mathrm{m}^{2}$. The cross section of annulus system is displayed in Figure 1 where the initial temperature of PCM is $330 \mathrm{~K}$. To enhance the rate of heat transfer and to overcome the less thermal conductivity of the $\mathrm{BW}$, three different kinds of nanoparticle $\left(\mathrm{Al}_{2} \mathrm{O}_{3}, \mathrm{SiO} 2\right.$, and $\left.\mathrm{MgO}\right)$ with high thermal conductivity are mixed into the beeswax. Thermophysical properties of the pure beeswax and the metal oxide nanoparticles are shown in Table 1 [7]. To execute numerical investigations on melting process of PCM system in suggested computational field, there are some assumptions which are considered:

(1) Liquefied phase of composite PCM system and the movement inside the annulus container is $\mathrm{New}$ tonian, laminar, and incompressible

(2) Volume extension or reduction of system related with phase alteration in annulus container is not considered

(3) Because container material contains higher thermal conductivity, the thickness of $(1 \mathrm{~mm})$ is ignored and variations of temperature are also ignored

(4) Boussinesq approximation is considered to calculate density difference and relevant buoyancy motivated natural convection

Current numerical solution acquired enthalpy-porous model in ANSYS Fluent15.0. All the units of length were fixed to $\mathrm{mm}$ and meshing quality was checked by grid independence test. Two-dimensional transient model with first-order implicit function was selected to solve the available problem. The melting solidification as well as energy was designated and mushy region is constant adopted as default value. Physical properties of the composite are entered in the material panel. The specific heat and thermal conductivity are fixed as constant and density follows to Boussinesq hypothesis. SIMPLE algorithm was used for coupling velocity and pressure parameter during solution. For converging the solution, second-order upwind scheme is adopted for energy equation. Finally, the monitor window is set accordingly for specific model and enters in the convergence and next iteration.

\section{Mathematical Model}

Enthalpy-porosity technique is widely used to study phase change problems nowadays. ANSYS fluent software has a code for solid-liquid phase alteration module according to this model. With the use of enthalpy model, the problem of phase alteration becomes simpler with some advantages; that is, the equation is governed with single phase, there is no way for interface meeting, and it occupies a mushy zone. To understand the melt front accurately, the used governing equation is as follows. 

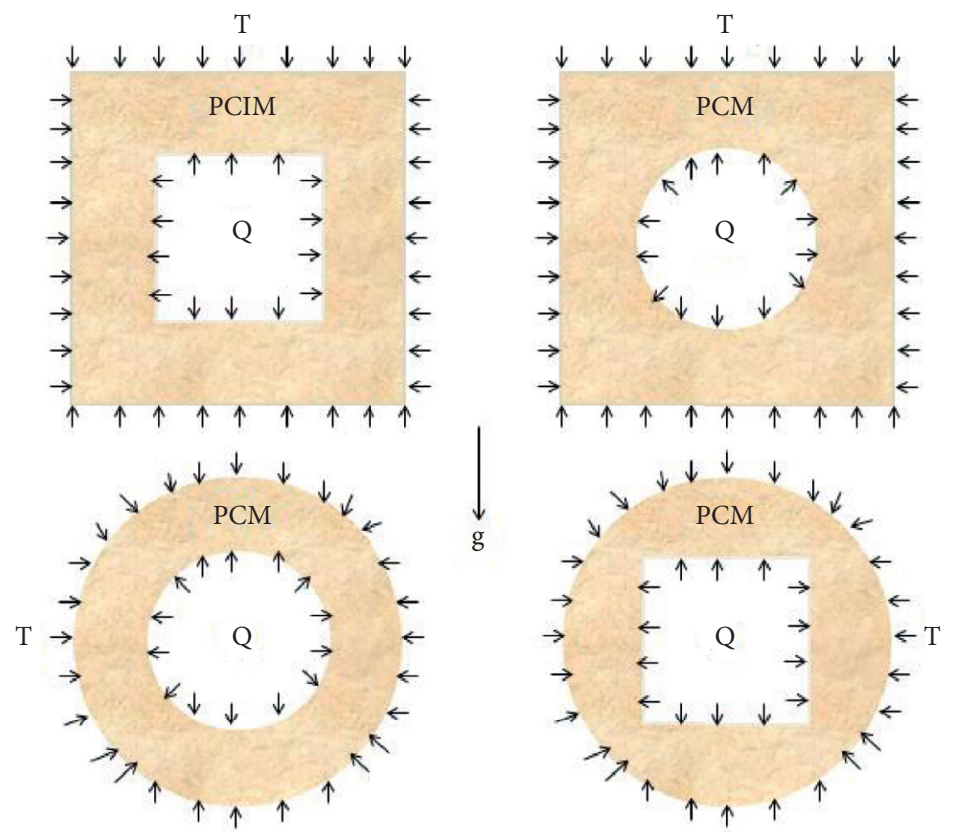

$\mathrm{T}$ - Temperature supplied to outer boundary

$\mathrm{Q}$ - Heat flux supplied to inner boundary

Figure 1: Schematic of beeswax PCM in different annulus systems.

TABLE 1: Thermophysical properties [13, 39].

\begin{tabular}{|c|c|c|c|c|}
\hline Properties & Beeswax & $\mathrm{Al}_{2} \mathrm{O}_{3}$ & $\mathrm{SiO}_{2}$ & $\mathrm{MgO}$ \\
\hline Density $\left(\mathrm{kg} / \mathrm{m}^{3}\right)$ & 961 & 3890 & 2650 & 3580 \\
\hline Specific heat at constant pressure $(\mathrm{J} / \mathrm{kg}-\mathrm{K})$ & 2093 & 778 & 753 & 921 \\
\hline Thermal conductivity $(W / \mathrm{m}-\mathrm{K})$ & 0.3 & 38.493 & 11.715 & 61.923 \\
\hline Solidification temperature $(\mathrm{K})$ & 331 & - & - & - \\
\hline Liquification temperature $(\mathrm{K})$ & 333.6 & - & - & - \\
\hline Latent heat of melting $(\mathrm{J} / \mathrm{kg})$ & 141490 & - & - & - \\
\hline Viscosity $(\mathrm{kg} / \mathrm{m}-\mathrm{sec})$ & 0.02461 & - & - & - \\
\hline Thermal expansion coefficient $(1 / \mathrm{K})$ & 0.00034 & - & - & - \\
\hline
\end{tabular}

Continuity equation:

$$
\frac{\partial \rho}{\partial t}+\frac{\partial \rho u}{\partial x}+\frac{\partial \rho u}{\partial y}=0
$$

Momentum equation:

$$
\begin{aligned}
& \rho\left[\frac{\partial u}{\partial t}+u \frac{\partial u}{\partial x}+v \frac{\partial u}{\partial y}\right]=-\frac{\partial p}{\partial x}+u\left(\frac{\partial^{2} u}{\partial x^{2}}+\frac{\partial^{2} u}{\partial y^{2}}\right)+s_{u} \\
& \rho\left[\frac{\partial u}{\partial t}+u \frac{\partial v}{\partial x}+v \frac{\partial v}{\partial y}\right]=-\frac{\partial p}{\partial y}+u\left(\frac{\partial^{2} v}{\partial x^{2}}+\frac{\partial^{2} v}{\partial y^{2}}\right)+s_{v}
\end{aligned}
$$

where $\mathrm{Su}$ and $\mathrm{Sv}$ represent appropriate momentum sink terms, which are added to account for the pressure drop caused by the solid material, as follows:

$$
\begin{aligned}
& s_{u}=\frac{(1-\gamma)^{2}}{\left(\gamma^{3}+\varepsilon\right)} A_{\text {mush }} u, \\
& s_{v}=\frac{(1-\gamma)^{2}}{\left(\gamma^{3}+\varepsilon\right)} A_{\text {mush }} v+\rho_{\text {ref }} g \alpha\left(T-T_{\text {ref }}\right) .
\end{aligned}
$$

$A_{\text {mush }}$ is the constant value for mushy zone lies between $10^{4}$ and $10^{7} . \varepsilon$ is the constant value below $10^{-4} \cdot \gamma$ is liquid volume fraction which could be obtained by

$$
\begin{array}{cl}
\gamma=1 & T \leq T_{S} \\
\frac{T-T_{S}}{T_{L}-T_{S}} & T \geq T_{L}
\end{array} .
$$

Note that $\gamma=0$ represent solid phase of PCM, $\gamma=1$ represents the liquid phase of the $\mathrm{PCM}$, and $0<\gamma<1$ is the indication of mushy zone.

Energy equation:

$$
\begin{aligned}
\rho\left[\frac{\partial H}{\partial t}+u \frac{\partial H}{\partial x}+v \frac{\partial H}{\partial y}\right] & =\frac{k}{c_{p}}\left(\frac{\partial^{2} H}{\partial x^{2}}+\frac{\partial^{2} H}{\partial y^{2}}\right)+s_{h}, \\
H & =h_{\text {ref }}+\int_{T_{\text {ref }}}^{T} C_{p} \mathrm{~d} T+\Delta H,
\end{aligned}
$$


where $h_{r e f}$ is enthalpy at reference temperature.

$$
\begin{aligned}
S_{h} & =\frac{\rho}{c_{p}} \frac{\partial(\Delta H)}{\partial t}, \\
\Delta H & =\gamma L .
\end{aligned}
$$

3.1. Composite PCM Thermophysical Properties Equations.

$$
\begin{aligned}
& \rho_{\mathrm{npcm}}=(1-\varnothing) \rho_{\mathrm{pcm}}+\varnothing \rho_{\mathrm{np}}, \\
& L_{\mathrm{npcm}}=\frac{(1-\varnothing) \rho_{\mathrm{pcm}} L_{\mathrm{pcm}}}{\rho_{\mathrm{npcm}}}, \\
& c_{p_{\mathrm{npcm}}}=\frac{(1-\varnothing) \rho_{\mathrm{pcm}} c_{p_{\mathrm{npcm}}}+\varnothing \rho_{\mathrm{np}} c_{p_{\mathrm{np}}}}{\rho_{\mathrm{npcm}}}, \\
& \beta_{\mathrm{npcm}}=\frac{(1-\varnothing) \rho_{\mathrm{pcm}} \beta_{\mathrm{pcm}}+\varnothing \rho_{\mathrm{np}} \beta_{\mathrm{np}}}{\rho_{\mathrm{npcm}}} .
\end{aligned}
$$

Thermal conductivity of the composite PCM that depends upon temperature, volume ratio, size of particle, properties of PCM, and properties of particle that is in Brownian motion is calculated with the help of the given equation (8).

The effective thermal conductivity of the composite PCM which includes the effects of particle size, particle volume fraction, and temperature dependence as well as properties of the base PCM and the particle subject to Brownian motion is given by

$$
\begin{aligned}
k_{\mathrm{npcm}}= & \frac{k_{\mathrm{np}}+2 k_{\mathrm{pcm}}-2 \varnothing\left(k_{\mathrm{pcm}}-k_{\mathrm{np}}\right)}{k_{\mathrm{np}}+2 k_{\mathrm{pcm}}+\varnothing\left(k_{\mathrm{pcm}}-k_{\mathrm{np}}\right)} \cdot k_{\mathrm{pcm}} \\
& +5.10^{4} \rho_{\mathrm{pcm}} \varnothing c_{p_{\mathrm{pcm}}} \sqrt{\frac{K_{B} T_{\mathrm{npcm}}}{\rho_{\mathrm{np}} d_{\mathrm{np}}}} f(T, \varnothing),
\end{aligned}
$$

where $K_{\mathrm{B}}$ is Boltzmann constant with value $1.38 \times 10^{-23} \mathrm{~J} / \mathrm{K}$ and $\mathrm{d}_{\mathrm{np}}$ is diameter of particle. $f(T, \varnothing)$ is correction factor which is defined as

$$
\begin{aligned}
f(T, \varnothing)= & \left(2.8217 \times 10^{-2} \varnothing+3.917 \times 10^{-3}\right) \frac{T_{\mathrm{npcm}}}{T_{\mathrm{ref}}} \\
& +\left(-3.0669 \times 10^{-2} \varnothing-3.91123 \times 10^{-3}\right) .
\end{aligned}
$$

Dynamic viscosity of composite is calculated as follows:

$$
\mu_{\mathrm{npcm}}=0.983 e^{(12.958 \varnothing)} \cdot \mu_{\mathrm{pcm}}
$$

\section{Grid Independence Test and Validation of the Numerical Model Used}

For accuracy of the model and mesh generation, grid independence test has been performed for the melt fraction and temperature variation. For the given model, four kinds of number of elements that is 20000, 30000, 40000, and
50000 have been chosen. The time dependent problem performs the calculation for $2500 \mathrm{sec}$ in cir-cir annulus and found the melt fraction and temperature variations shown in Figure 2. These results show that the variation of melt fraction and temperature is in little manner for all the four numbers of elements. The error percentage of two consecutive grid sizes has been taken into account and we found that the error is less than 0.05 percent for all the cases. So, for less solution time, 20000 elements is chosen for the calculations.

For any mathematical model used in engineering problem, it is an important task to investigate the validity of the proposed model. So, for validation, the comparative analysis of obtained numerical results with available experimental or numerical results is performed. In a short note, it is a routine operation in every numerical problem. In the present case, the accuracy for numerical model has been compared by the experiment results available in the literature [40]. Al-Abidi et al. [40] examined the enhancement of heat transfer through external and internal fins in triplex tube heat exchanger for melting of PCM experimentally as well as numerically. For numerical investigation, a two-dimensional ANSYS model was also developed by the researcher, where natural convection and pure conduction were considered for the simulation. The experimental results have provided the PCM average temperature during melting which is given in Figure 3. It was shown that the HTF temperature is at $363 \mathrm{~K}$, which flows at the mass flow rate of $8.3 \mathrm{~L} / \mathrm{min}$ and initial average temperature of PCM is at $300 \mathrm{~K}$. The melting range of the PCM was in between $343 \mathrm{~K}$ and $355 \mathrm{~K}$ which is shown in the experimentation. As seen from Figure 3, the results of current model revealed worthy agreement with experimental results at the time of the melting. That is why the present model exhibited an acceptable behaviour for further investigations.

\section{Results and Discussion}

5.1. Variation of Average Liquid Fraction and Temperature with respect to Time for Pure Beeswax. Thermal behavior of beeswax is simulated according to the given numerical model and initial boundary condition. With the application of HTF temperature and heat flux from outer and inner walls, respectively, the different annulus PCM system starts heating sensibly in the beginning time. When the time is spent, the annulus PCM system temperature reaches the phase alteration temperature; at this time, the interface of phase change initiate and system starts capturing latent heat. Now, the PCM is at that condition where solid as well as liquid both phase occurred simultaneously and the system attains mushy zone where the temperature of system remains constant. Afterwards, when the system completely melts, the system temperature increases sensibly. In the phase change heat transmission model, the efficiency of heat transfer of PCM is significantly affected by temperature field, phase change interface, maximum temperature, and minimum temperature. 


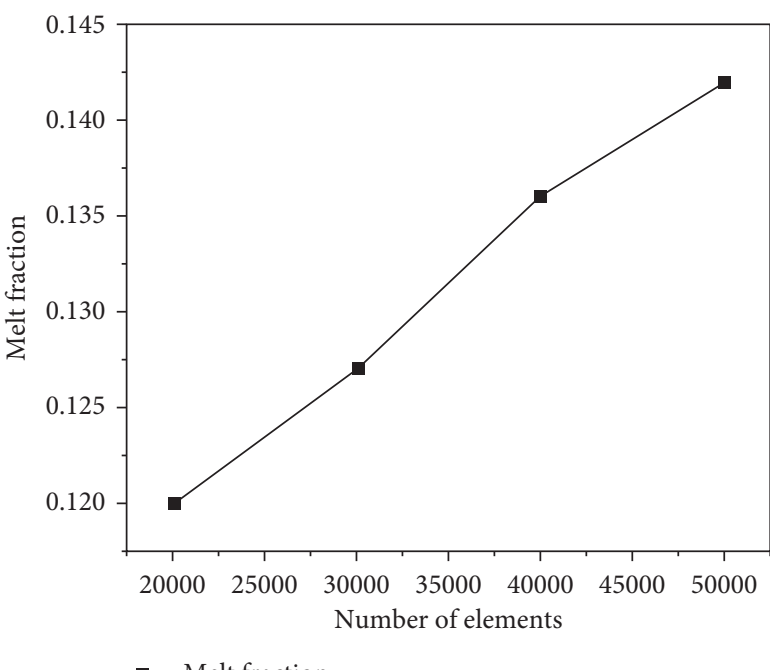

(a)

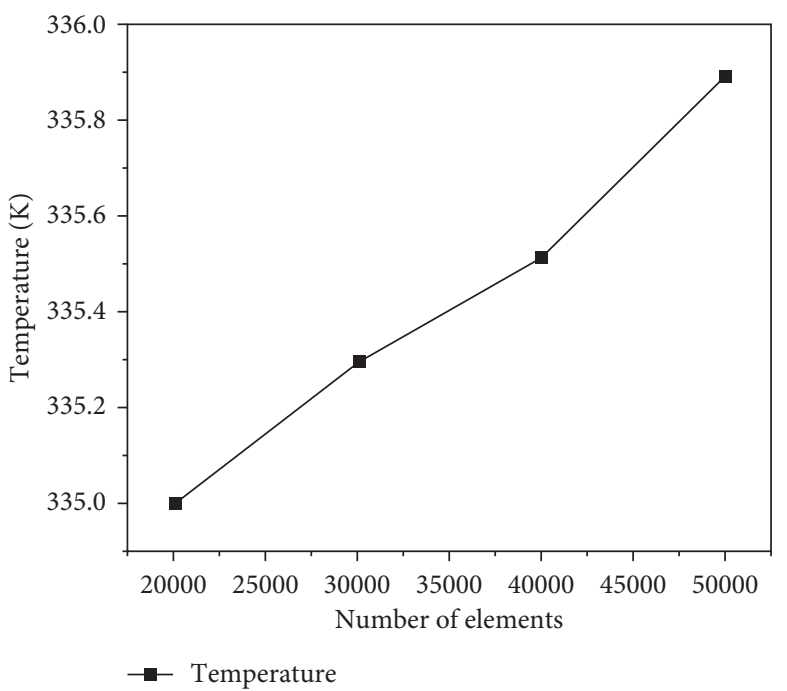

(b)

Figure 2: Variation of melt fraction and temperature for different number of elements.

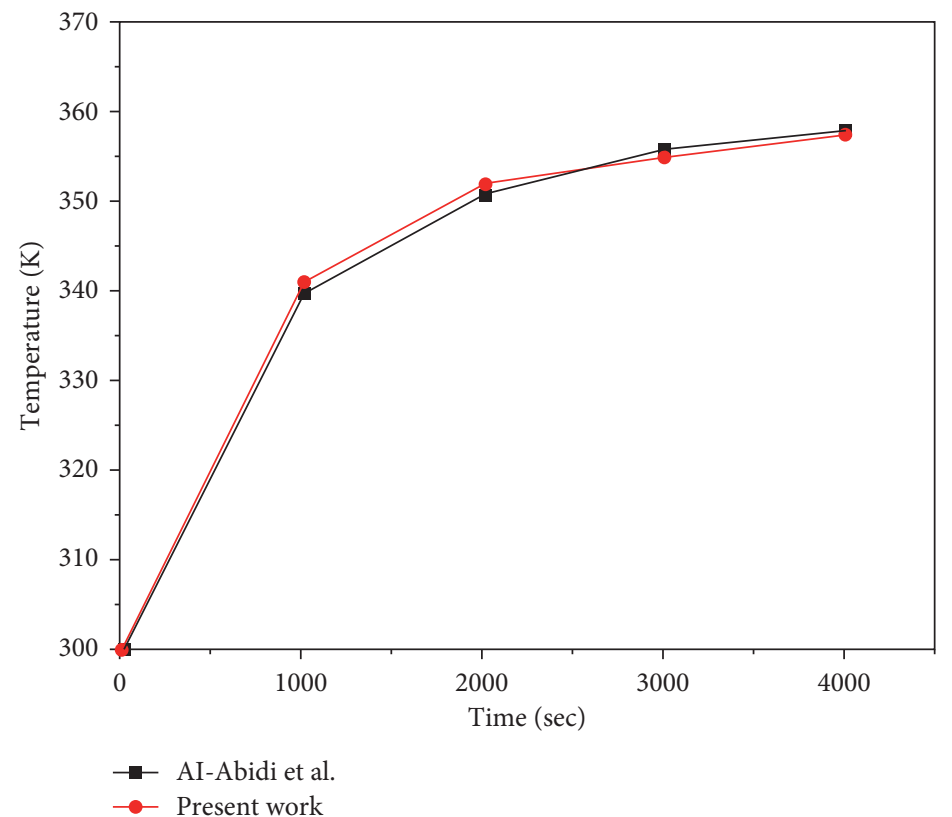

FIGURE 3: Model validation through comparing the average temperature profiles by Al-Abidi et al. and present work.

5.1.1. Phase Interface. Table 2 displays the phase alteration interface progress cloud diagram of different annulus beeswax system after various heating time. The solid-liquid boundary can be differentiated by colour design of the melt volume fraction. The boundary of solid-liquid in the cloud diagram is denoted by $0-1$. Solid phase is the blue area shown by 0 in colour cloud during phase transformation process and liquid phase in red area shown by 1 . In the initial investigation, a constant HTF temperature and heat flux are applied at outer and inner part of different annulus PCM for $1000 \mathrm{sec}$ and we found that few zones of the PCM attend 100\% melt fraction; at the same time, temperature of inner and outer wall increased sharply. The melting space begins to appear from both sides of annulus and a slim phase transformation interface appears. When the PCM sample is heated for 2500 $\mathrm{sec}-15000 \mathrm{sec}$, most part of the annulus PCM melts completely and as the time increases melt fraction reaches $100 \%$. The completely melted zones are displayed on both sides of the annulus and a temperature zone of 330-345 K appears in large phase alteration boundary. The reason behind the accumulation of big amount of latent heat is that the melting temperature range of the PCM is $330-345 \mathrm{~K}$ at the time of phase change, leading to a broader mushy zone. From Figure 4, the average melt fraction of different annulus shape PCM system for different time zones is revealed. The melt fraction varies from 0.12 to 0.58 for cir-cir shape, 0.13 to 0.6 for cir-rec case, 0.14 to 0.62 for rec-cir case, and 0.145 to 0.64 for rec-rec case when time varies from 2500 to $15000 \mathrm{sec}$. 
TABLE 2: Liquid fraction contours of four different annulus shapes during the melting.

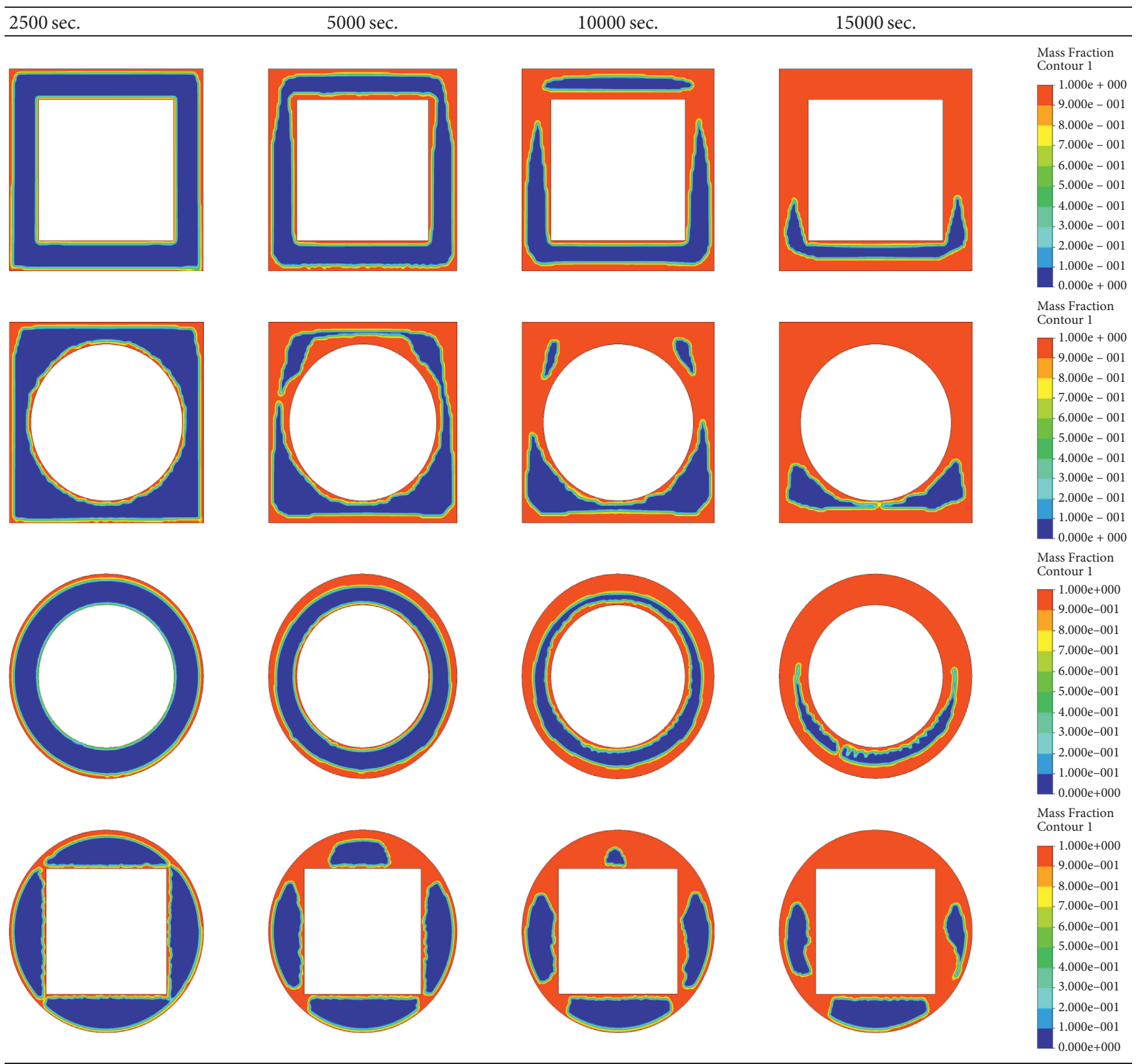

These data show that rec-rec shape annulus PCM system melts $10 \%$ more compared to cir-cir, $6 \%$ more compared to cir-rec, and 3.2\% compared to rec-cir annulus shape. So, the rec-rec annulus PCM system melts little faster compared to other system. Heat transfer is arbitrated by the temperature gradient, material properties, and the system configuration. In the present case, temperature gradient and material properties are the same for all cases; the only variation is in its configuration. Transfer of heat is diffusive in nature and based on transformation thermodynamics heat flow reflects directionally like the mirror for light beam. So, for the rec-rec configuration, the direction of heat flow distortion is very less compared to other configuration that means less thermal resistance. The losses of heat energy in this case are very less and dominating in melting than others.
5.1.2. Phase Transition Temperature Field. Table 3 is the illustration of temperature field colour cloud at various heating time of the beeswax PCM annulus system. The colour contour of the annulus system provides details about the range of temperature in the unit K. From the variation of temperature range, it is illustrated that the variations in temperature lie between 330 and $345 \mathrm{~K}$ at the time of phase alteration. When the annulus beeswax system is heated for initial $2500 \mathrm{sec}$, the heat conduction starts due to constant HTF temperature from inner side of annulus and constant heat flux on outer side of the annulus. Due to the application of heat energy, a temperature difference occurs in the inner and outer part and wall temperature increases quickly. Initially, a steady-state temperature achieves in very short period of time because the inner and outer wall temperature 


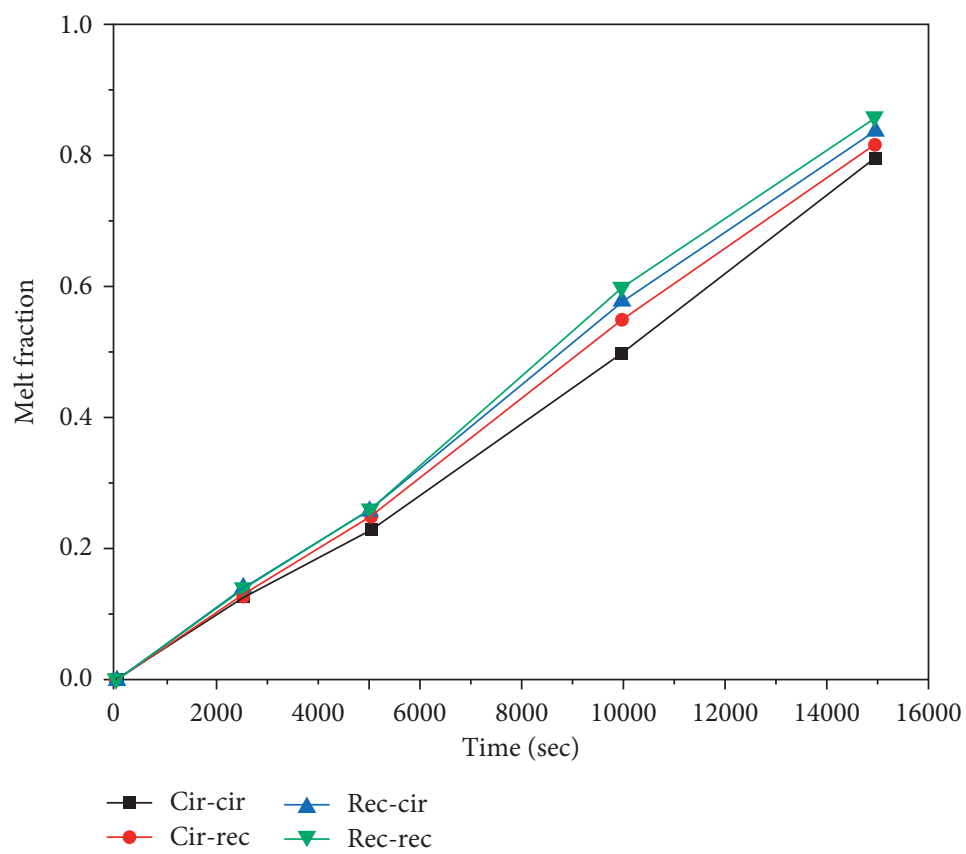

FIGURE 4: Melt fraction evolution of different BW annulus PCM systems with time.

TABLE 3: Temperature contours of four different annulus shapes during the melting.

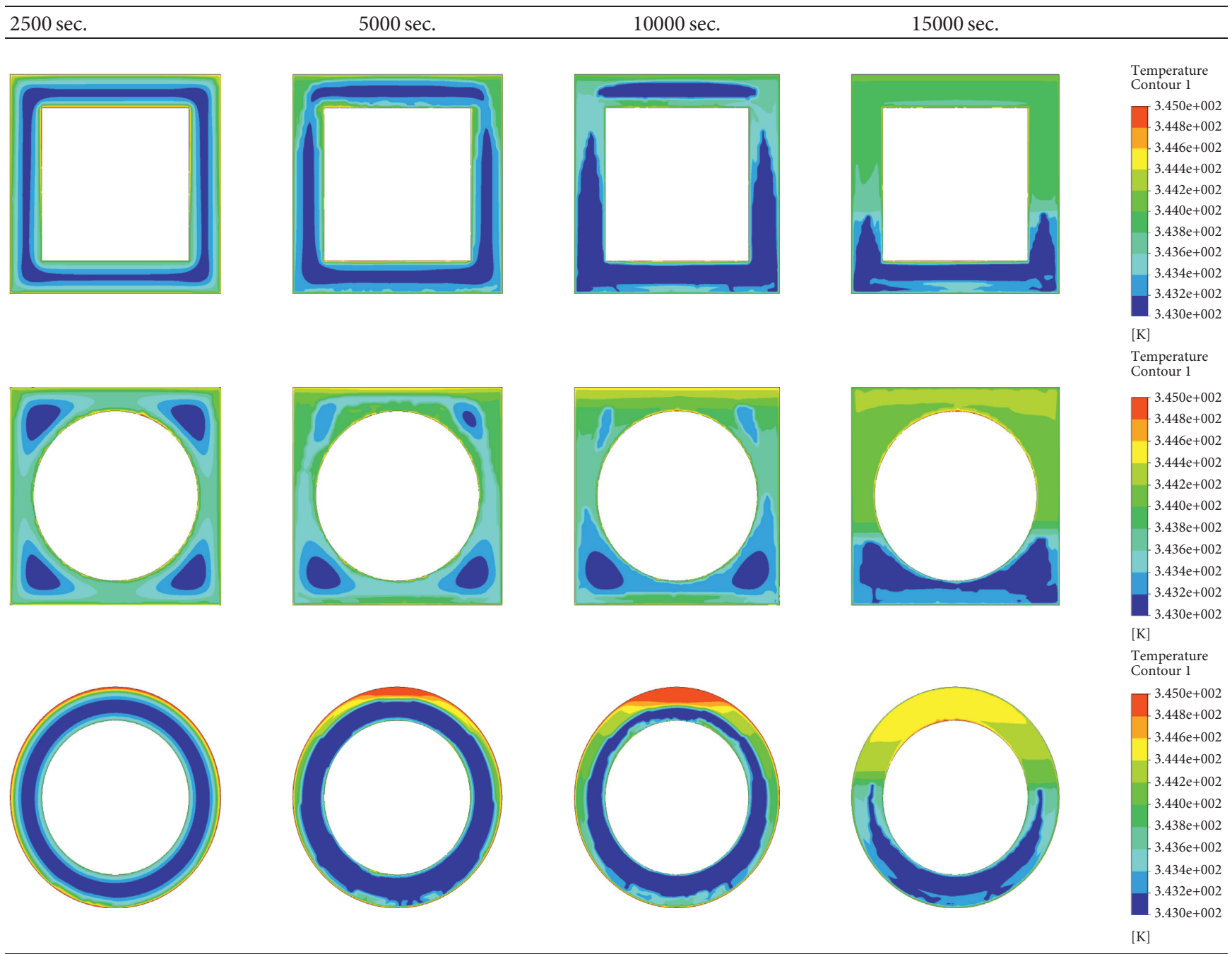


TABLE 3: Continued.

$2500 \mathrm{sec.} 5000 \mathrm{sec}$.

of the PCM increases rapidly. In this initial time, a very small portion of the energy storage material completely melts and the peak temperature reaches $345 \mathrm{~K}$. At the time when annulus sample is heated for $5000 \mathrm{sec}-10000 \mathrm{sec}$, the mode of heat transfer is dominated by convection, and melting of the annulus PCM system moves towards solid part from inner and outer side. Meanwhile, in the mushy zone where slow increment in temperature has huge amount of phase alteration, latent heat and the lowest temperature occur inside the temperature field somewhere between inner and outer wall. The peak or extreme temperature reached the wall. When mushy zone is finished, the annulus system melts completely. This is because the supplied heat is no more used for melting or not for utilizing in latent heat absorption. When the heating time reached $15000 \mathrm{sec}$, the whole annulus system achieved the phase alteration temperature and the peak temperature at this time reaches $345 \mathrm{~K}$ but the entire system is not melted completely. The gained liquid area is heated sensibly at this time. In the phase transition from solid to liquid, when time is spent, the heat transfer due to convection starts to dominate over conduction and the liquid region moves up and down rapidly.

Figure 5 reveals the average temperature of different annulus shape PCM system for different time zone. The temperature varies from 335 to $341 \mathrm{~K}$ for cir-cir shape, 335.4 to 341.4 for cir-rec case, 335.6 to 341.6 for rec-cir case, and 335.8 to 341.8 for rec-rec case when time varies from 2500 to $15000 \mathrm{sec}$. These data show that temperature rise of rec-rec shape annulus PCM system is $0.2 \%$ more compared to circir, $0.1 \%$ more compared to cir-rec, and $0.05 \%$ compared to rec-cir annulus shape. Results show that there is a negligible effect of temperature variation in all the cases.

\subsection{Variation of Average Liquid Fraction and Temperature} with respect to Time for Composite-Beeswax. The overall thermal performance of the annulus PCM area with different shape annulus container shown in Figure 1, under the effect of various nanoparticles $\left(\mathrm{Al}_{2} \mathrm{O}_{3}, \mathrm{SiO}_{2}\right.$, and $\left.\mathrm{MgO}\right)$ distribution into the beeswax PCM, is discovered. The average melt fraction and temperature for three metal oxides with three volume fraction concentrations of nanoparticles $(1 \%, 3 \%$, and $5 \%)$ are explored. The low volume fraction participation of particles ( $5 \%$ maximum) slightly affects the thermophysical properties of the resulting composite PCM.
However, there is no suggestion for utilization of high concentration of particles; with the loss of mass of PCM, the heat storage volume of the system reduces. At the same time, particle concentration increases the composite viscosity that causes the loss of heat exchange [41]. The heat transfer process dominates by natural convection in the case of melting; as the viscosity increases, the buoyancy of the fluid reduces which leads to slowing of the melting procedure [42]. From the results shown below, it is shown that the addition of nanoparticles in a very little proportion could increase thermal conductivity of the beeswax that is the major cause for quick increment of melt fraction and annulus temperature. But higher proportion of particles could upsurge the composite viscosity which causes the temperature quenching in the PCM that affects the melting rate of PCM [43]. It is noted that as the nanoparticle concentration increases, the energy storage by the composite PCM decreases, because the increment of particle fraction decreases the occupied volume of base PCM. Hence, less particles concentration in PCM does not only show healthier melting behaviour but also have greater energy storage performance for a given annulus compared with higher concentrations of particles. The results found for average melt fraction and temperature of different annulus beeswax at different nanoparticle concentrations are discussed in the next sections.

5.2.1. Evolution of Melt Fraction and Temperature in Cir-Cir Annulus PCM. From Figures 6 and 7 it is revealed that both the average melt fraction and temperature are meaningfully improved in the presence of nanomaterials. It is remarked that, due to the slight variation in thermophysical properties of the particles, there is no critical variation in rate of heat transfer and phase transformation. For the three examined metal oxide particles, the temperature rise in the cir-cir annulus composite PCMs attained $340 \mathrm{~K}$ in case of $1 \%$ volume fraction for $\mathrm{Al}_{2} \mathrm{O}_{3}$, at $2500 \mathrm{sec}$ and $346 \mathrm{~K}$ for $15000 \mathrm{sec}$, whereas, as noted for the pure BW PCM at the time of $2500 \mathrm{sec}$ and $15000 \mathrm{sec}$, it is $335 \mathrm{~K}$ and $341 \mathrm{~K}$, which shows an improvement of $1.49 \%$ and $1.46 \%$. The liquid fraction for the same condition increases from 0.12 at $2500 \mathrm{sec}$ and 0.58 at $15000 \mathrm{sec}$ for the pure BW to 0.2 at $2500 \mathrm{sec}$ and 0.88 at $15000 \mathrm{sec}$, respectively. It is shown from the results that the melting 


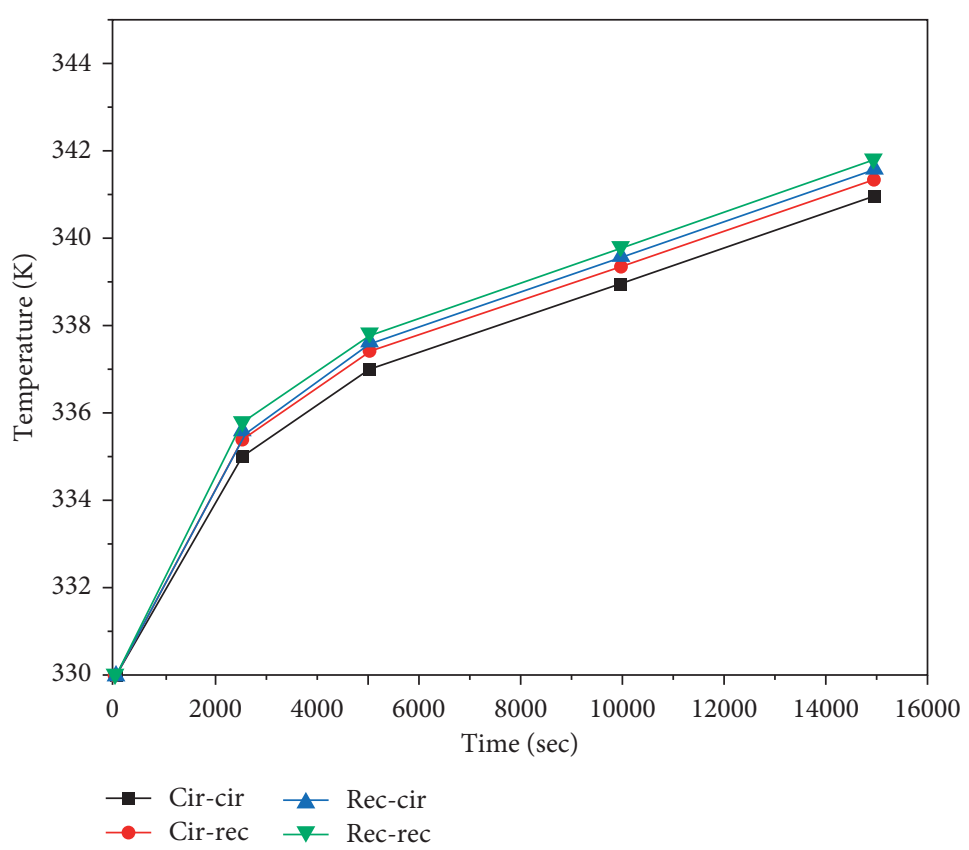

Figure 5: Temperature evolution of BW annulus PCM with time.

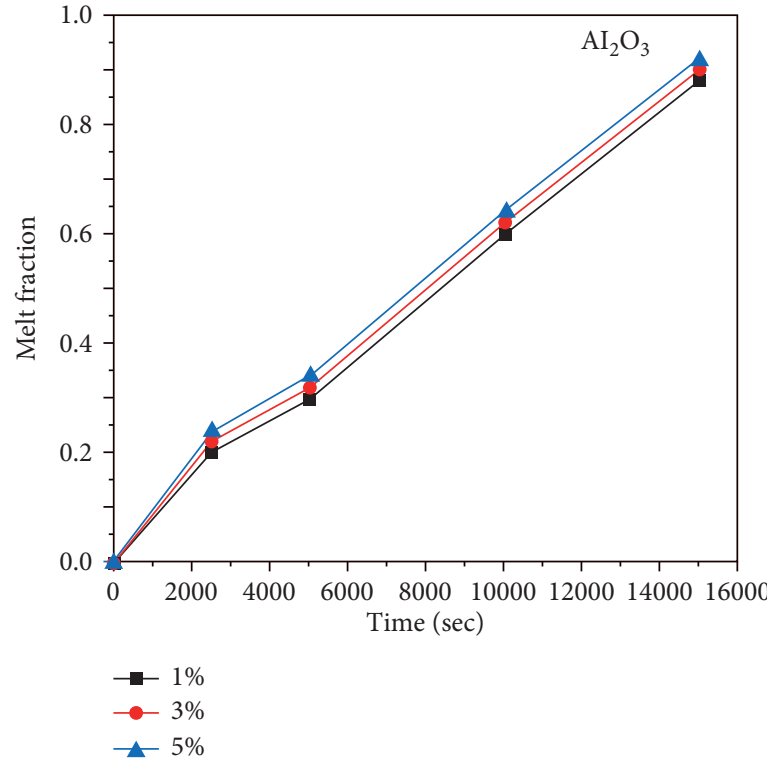

(a)

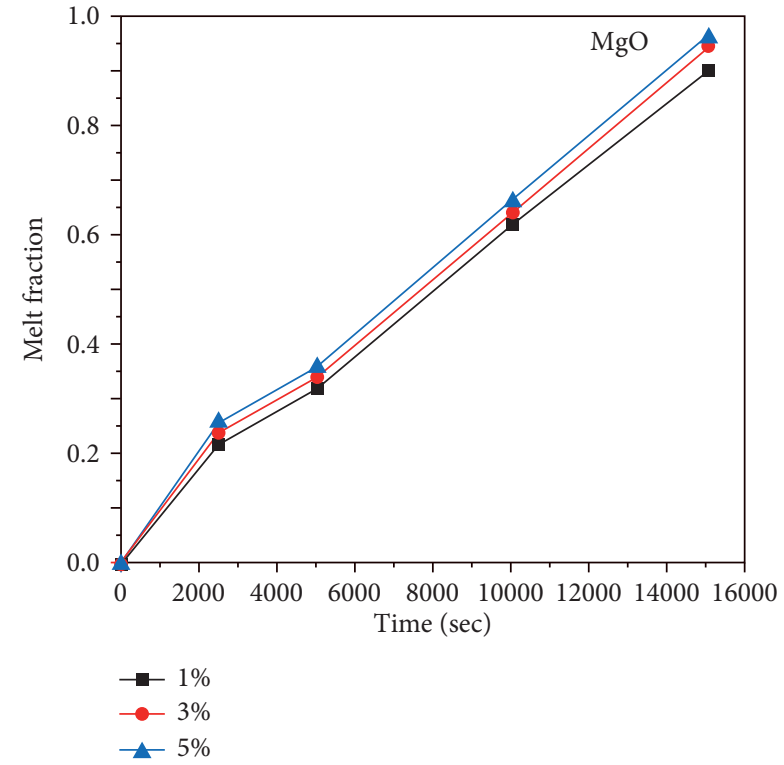

(b)

Figure 6: Continued. 


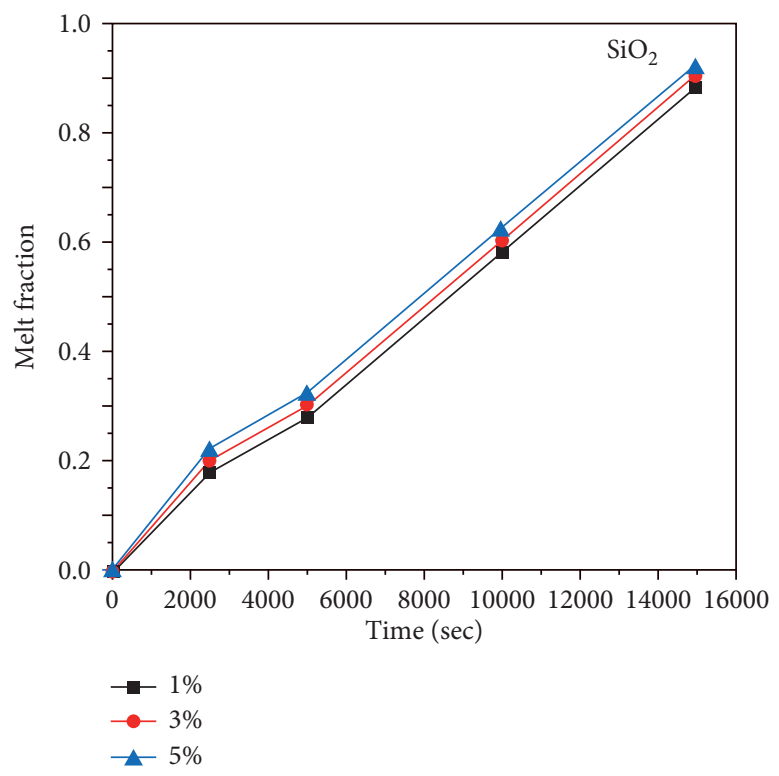

(c)

FIGURE 6: Melt fraction evolution in cir-cir annulus PCM with time and nanoparticle concentration.

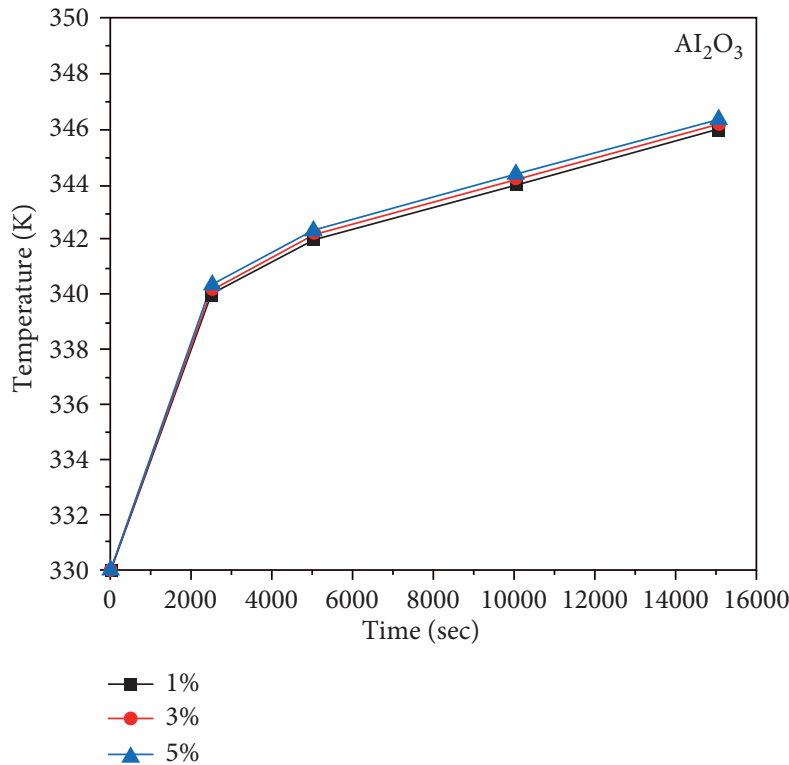

(a)

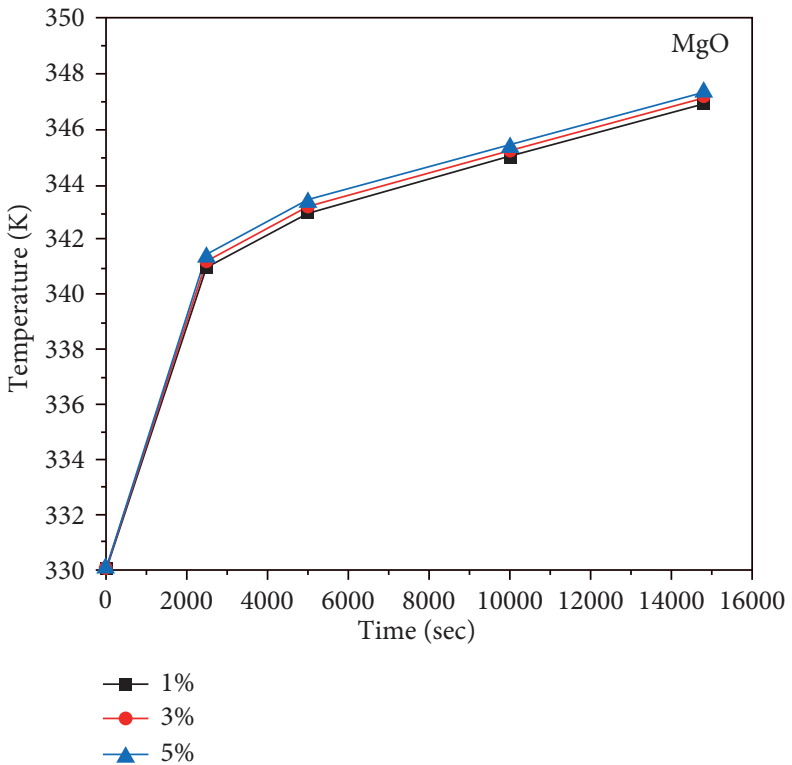

(b)

Figure 7: Continued. 


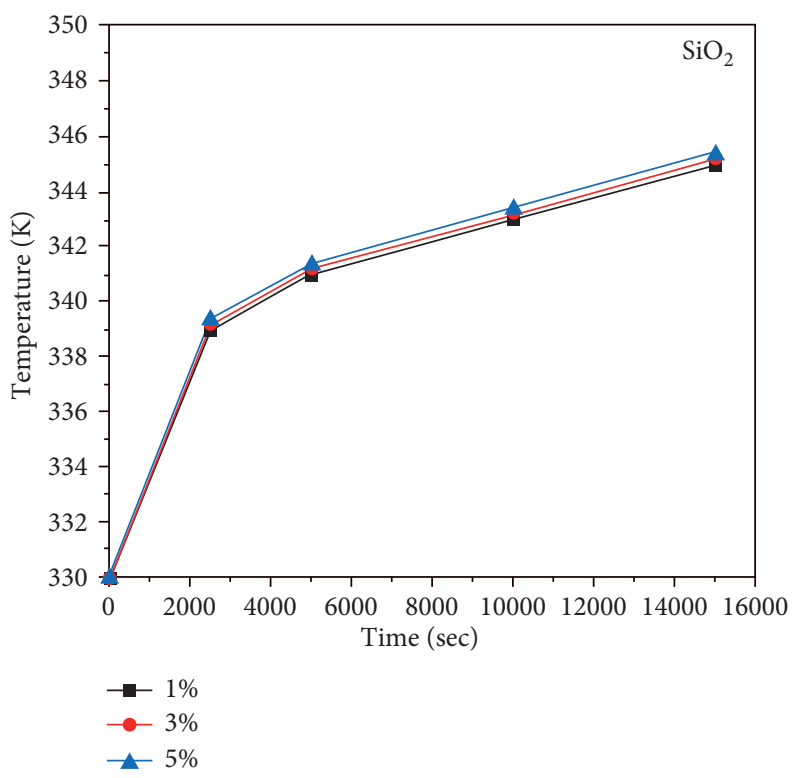

(c)

FIgURE 7: Temperature evolution in cir-cir annulus PCM with time and nanoparticle concentration.

yield enhanced by $66.66 \%$ and $51.72 \%$ when compared to pure BW. For the melt fraction, when the time goes to $5000 \mathrm{sec}, 10000 \mathrm{sec}$, and $15000 \mathrm{sec}$ by incorporating $1 \%$, $3 \%$, and $5 \%$ of nanoparticles, the increment of liquid fraction becomes $0.9,0.92$, and 0.94 for $\mathrm{Al}_{2} \mathrm{O}_{3} ; 0.88,0.9$, and 0.924 for $\mathrm{SiO}_{2}$; and $0.92,0.943$, and 0.962 for the $\mathrm{MgO}$. At the same time, the temperature increment, when the time goes to $5000 \mathrm{sec}, 10000 \mathrm{sec}$, and $15000 \mathrm{sec}$ by adding $1 \%, 3 \%$, and $5 \%$ of nanoparticles, is $346.2 \mathrm{~K}, 346.412 \mathrm{~K}$, and $346.6 \mathrm{~K}$ for $\mathrm{Al}_{2} \mathrm{O}_{3} ; 345,345.2$, and 345.4 for $\mathrm{SiO}_{2}$; and 347 , 347.2, and 347.4 for $\mathrm{MgO}$.

5.2.2. Evolution of Melt Fraction and Temperature in Cir-Rec Annulus PCM. From Figures 8 and 9, it is shown that, for three investigated metal oxides, the temperature gain in the cirrec annulus composite PCMs attained $340.2 \mathrm{~K}$ in case of $1 \%$ volume fraction for $\mathrm{Al}_{2} \mathrm{O}_{3}$, at $2500 \mathrm{sec}$ and $346.2 \mathrm{~K}$ for $15000 \mathrm{sec}$, whereas, as noted for the pure BW PCM at the time of $2500 \mathrm{sec}$ and $15000 \mathrm{sec}$, it is $335.3 \mathrm{~K}$ and $341.4 \mathrm{~K}$, which shows an improvement of $1.46 \%$ and $1.4 \%$. The liquid fraction for the same condition increases from 0.13 at $2500 \mathrm{sec}$ and 0.6 at $15000 \mathrm{sec}$ for the pure BW to 0.21 at $2500 \mathrm{sec}$ and 0.91 at $15000 \mathrm{sec}$, respectively. It is shown from the results that the melting yield enhanced by $61.53 \%$ and $51.66 \%$ when compared to pure BW. For the melt fraction, when the time goes to $5000 \mathrm{sec}, 10000 \mathrm{sec}$, and $15000 \mathrm{sec}$ by incorporating 1\%, 3\%, and $5 \%$ of nanoparticles, the increment of liquid fraction to $0.91,0.93$, and 0.95 for $\mathrm{Al}_{2} \mathrm{O}_{3} ; 0.89,0.915$, and 0.93 for $\mathrm{SiO}_{2}$; and $0.89,0.91$, and 0.932 for the $\mathrm{MgO}$, whereas the temperature increment, when the time goes to $5000 \mathrm{sec}, 10000 \mathrm{sec}$, and $15000 \mathrm{sec}$ by adding $1 \%, 3 \%$, and $5 \%$ of nanoparticles, is $346.2 \mathrm{~K}, 346.412 \mathrm{~K}$, and $346.6 \mathrm{~K}$ for $\mathrm{Al}_{2} \mathrm{O}_{3} ; 345.23,345.4$, and 345.612 for $\mathrm{SiO}_{2}$; and 347.24, 347.41, and 347.62 for $\mathrm{MgO}$.
5.2.3. Evolution of Melt Fraction and Temperature in Rec-Cir Annulus PCM. From Figures 10 and 11, considering the three investigated metal oxides, the temperature gain in the rec-cir annulus composite PCMs attained $340.4 \mathrm{~K}$ in case of $1 \%$ volume fraction for $\mathrm{Al}_{2} \mathrm{O}_{3}$, at $2500 \mathrm{sec}$ and $346.4 \mathrm{~K}$ for $15000 \mathrm{sec}$, whereas, as noted for the pure BW PCM at the time of $2500 \mathrm{sec}$ and $15000 \mathrm{sec}$, it is $335.6 \mathrm{~K}$ and $341.6 \mathrm{~K}$, which shows an improvement of $1.43 \%$ and $1.4 \%$. The liquid fraction for the same condition increases from 0.14 at $2500 \mathrm{sec}$ and 0.62 at $15000 \mathrm{sec}$ for the pure BW to 0.22 at $2500 \mathrm{sec}$ and 0.92 at $15000 \mathrm{sec}$, respectively. It is shown from the results that the melting yield enhanced by $57.14 \%$ and $48.3 \%$ when compared to pure BW. For the melt fraction, when the time goes to $5000 \mathrm{sec}, 10000 \mathrm{sec}$, and $15000 \mathrm{sec}$ by incorporating 1\%, $3 \%$, and $5 \%$ of particles, the increment of liquid fraction was $0.92,0.94$, and 0.96 for $\mathrm{Al}_{2} \mathrm{O}_{3} ; 0.88,0.9$, and 0.92 for $\mathrm{SiO}_{2}$; and $0.94,0.96$, and 0.98 for the $\mathrm{MgO}$, whereas the temperature increment, when the time goes to $5000 \mathrm{sec}, 10000 \mathrm{sec}$, and $15000 \mathrm{sec}$ by adding $1 \%, 3 \%$, and $5 \%$ of nanoparticles, is $346.4 \mathrm{~K}, 346.62 \mathrm{~K}$, and $346.79 \mathrm{~K}$ for $\mathrm{Al}_{2} \mathrm{O}_{3} ; 345.4,345.6$, and 345.8 for $\mathrm{SiO}_{2}$; and 347.4, 347.6, and 347.8 for $\mathrm{MgO}$.

5.2.4. Evolution of Melt Fraction and Temperature in Rec-Rec Annulus PCM. The average liquid fraction and temperature are shown in Figures 12 and 13. It is found that heat transfer properties enhanced significantly in the presence of metal oxides nanomaterials. The rise in temperature for rec-rec annulus composite PCMs in the case of three investigated metal oxides was found as $340.6 \mathrm{~K}$ in case of $1 \%$ volume fraction for $\mathrm{Al}_{2} \mathrm{O}_{3}$, at $2500 \mathrm{sec}$ and $346.7 \mathrm{~K}$ for $15000 \mathrm{sec}$, whereas it is noted for the pure BW PCM at the time of $2500 \mathrm{sec}$ and $15000 \mathrm{sec}$ as $335.8 \mathrm{~K}$ and $341.9 \mathrm{~K}$, which shows an improvement of $1.43 \%$ and $1.4 \%$. The liquid fraction for the same condition increases from 


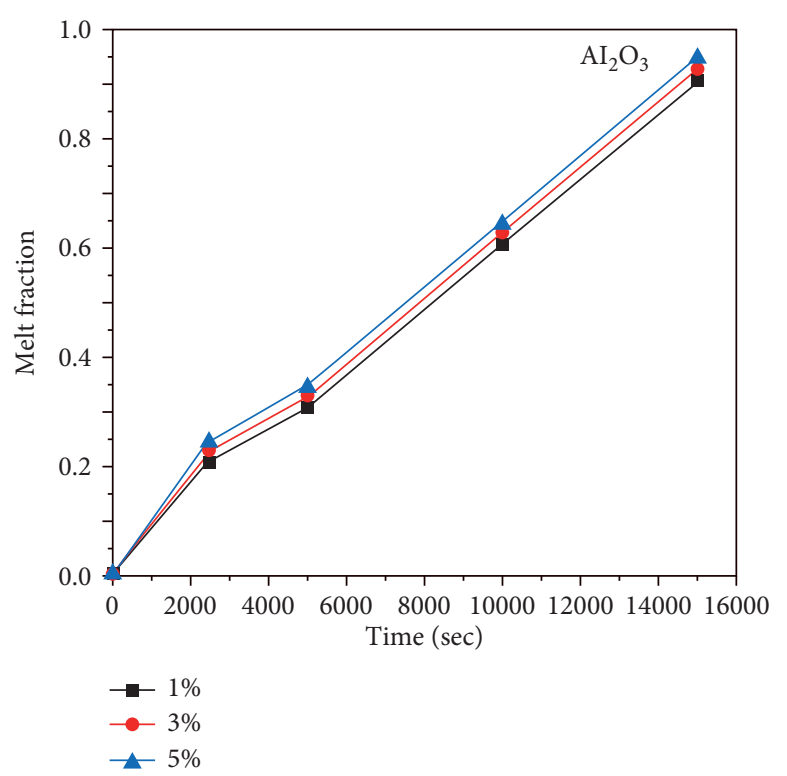

(a)

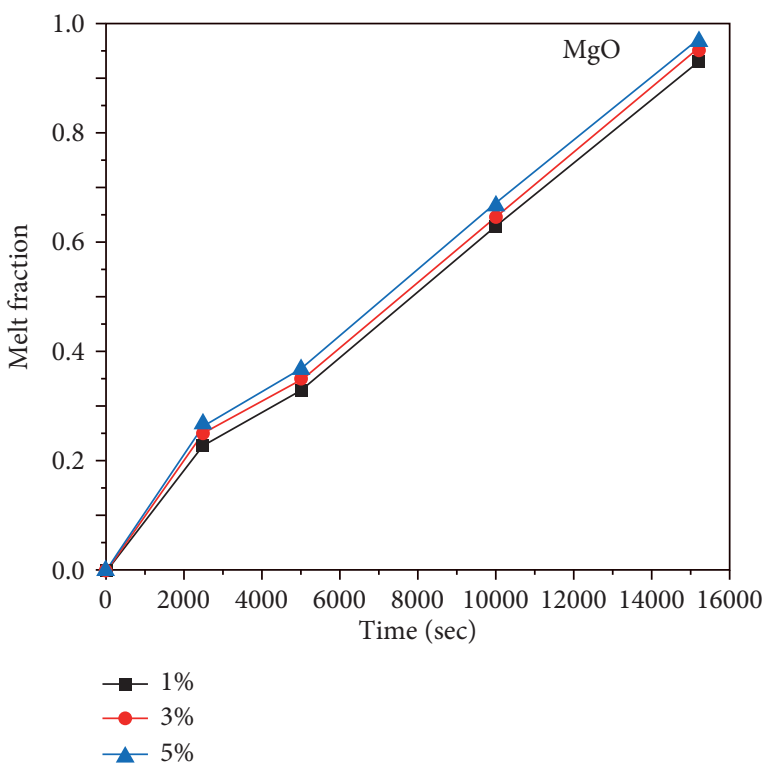

(b)

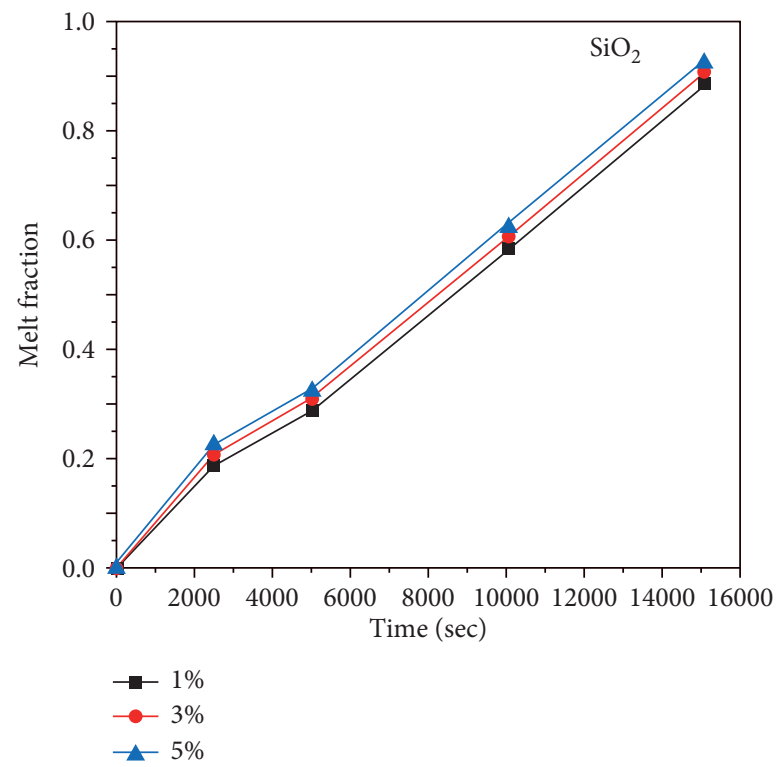

(c)

Figure 8: Melt fraction evolution in cir-rec annulus PCM with time and nanoparticle concentration.

0.145 at $2500 \mathrm{sec}$ and 0.64 at $15000 \mathrm{sec}$ for the pure BW to 0.23 at $2500 \mathrm{sec}$ and 0.93 at $15000 \mathrm{sec}$, respectively. It is shown from the results that the melting yield enhanced by $58.6 \%$ and $45.3 \%$ when compared to pure BW. For the melt fraction, when the time goes to $5000 \mathrm{sec}, 10000 \mathrm{sec}$, and $15000 \mathrm{sec}$ with the addition of $1 \%, 3 \%$, and $5 \%$ of nanoparticles, the increment of liquid fraction was to 0.93 , 0.95, and 0.97 for $\mathrm{Al}_{2} \mathrm{O}_{3} ; 0.91,0.93$, and 0.95 for $\mathrm{SiO}_{2}$; and $0.95,0.97$, and 0.99 for the $\mathrm{MgO}$, whereas the temperature increment, when the time goes to $5000 \mathrm{sec}, 10000 \mathrm{sec}$, and $15000 \mathrm{sec}$ by adding $1 \%, 3 \%$, and $5 \%$ of nanoparticles, is $346.6 \mathrm{~K}, 346.8 \mathrm{~K}$, and $347 \mathrm{~K}$ for $\mathrm{Al}_{2} \mathrm{O}_{3} ; 345.6 \mathrm{~K}, 345.8 \mathrm{~K}$, and $346 \mathrm{~K}$ for $\mathrm{SiO}_{2}$; and $347.6 \mathrm{~K}, 347.8 \mathrm{~K}$, and $348 \mathrm{~K}$ for $\mathrm{MgO}$.

5.3. Effect of Stefan Number and Rayleigh Number on the Melt Fraction. Stefan number signifies relation between sensible and latent heat area during heating process. In PCM heating 


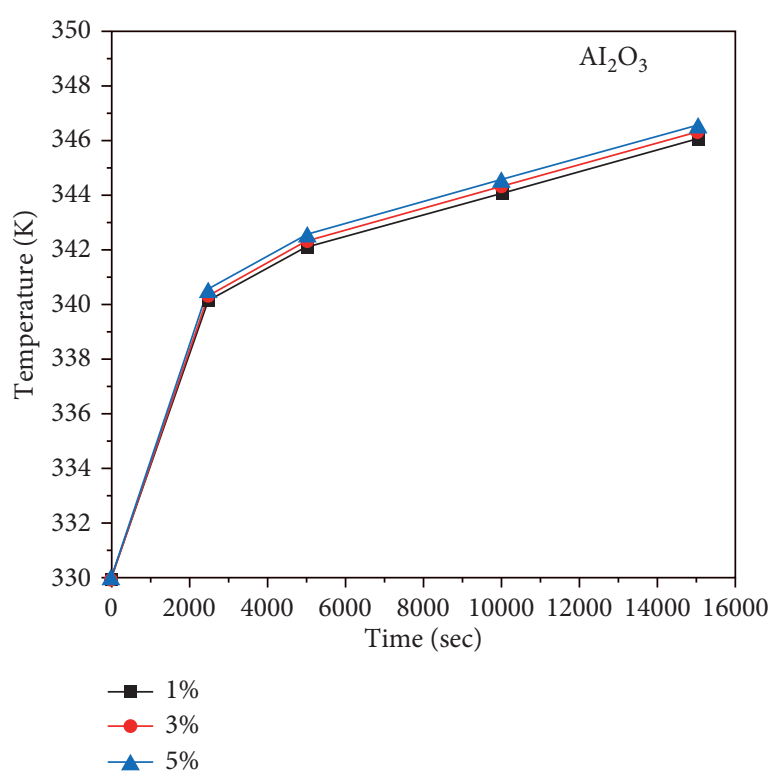

(a)

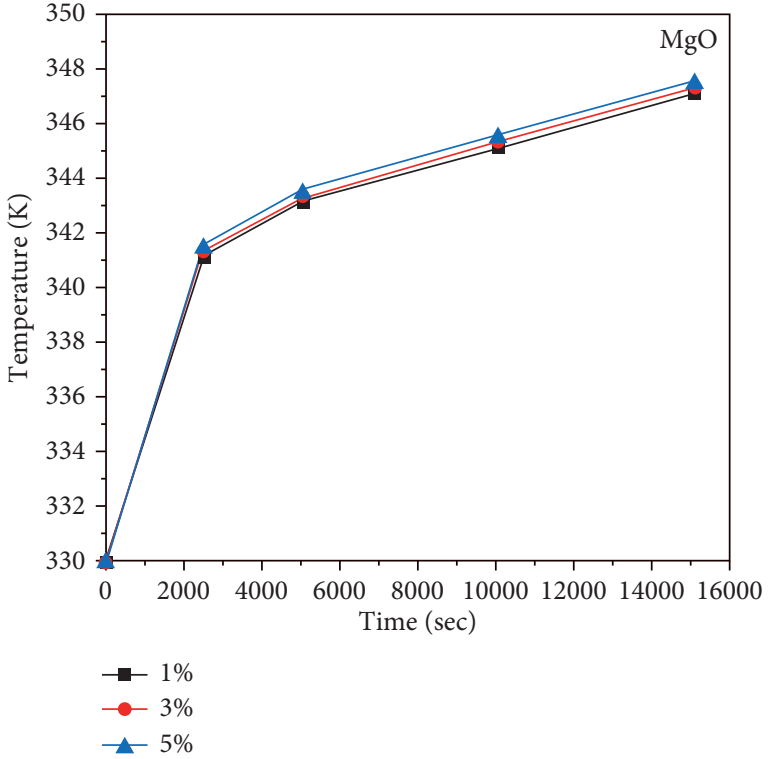

(b)

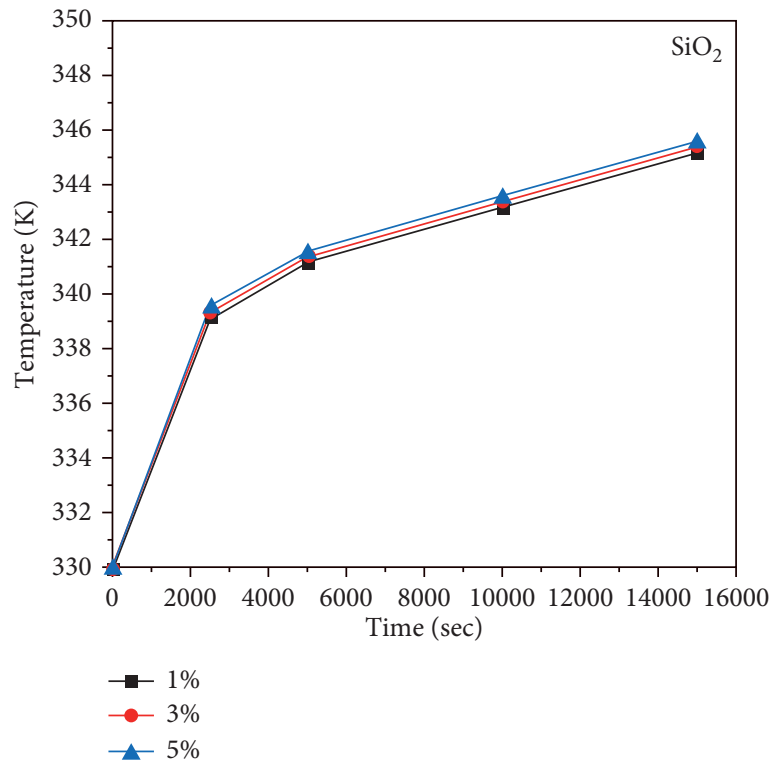

(c)

Figure 9: Temperature evolution in cir-rec annulus PCM with time and nanoparticle concentration.

process, the change in temperature difference reflects a change in Stefan number and is formulated as

$$
\text { Ste }=\frac{c_{p}\left(T-T_{m}\right)}{L},
$$

where $C_{p}$ is PCM specific heat, $L$ is PCM latent heat, $T$ is surface temperature, and $T_{m}$ is PCM melting temperature; Stefan number directly depends upon the temperature difference as the higher the difference, the higher the Stefan number value. The melt fraction with time for three different Stefan numbers of $0.044,0.073$, and 0.118 for three temperature differences gives the idea about operating situation at the time of melting process of annulus PCM system. It can be revealed from Figure 14 that surface temperature and melting temperature during the heat transfer process of PCM affects the melting rate; the more the temperature difference, the higher the rate of the melt fraction increment and the shorter the melting time.

Rayleigh number shows the strength of the convection induced inside annulus system domain. High value of Rayleigh number means higher convective current causing faster melting method. The Rayleigh number is formulated as

$$
R_{a}=\frac{\beta g \Delta T L^{3}}{\alpha \vartheta} .
$$




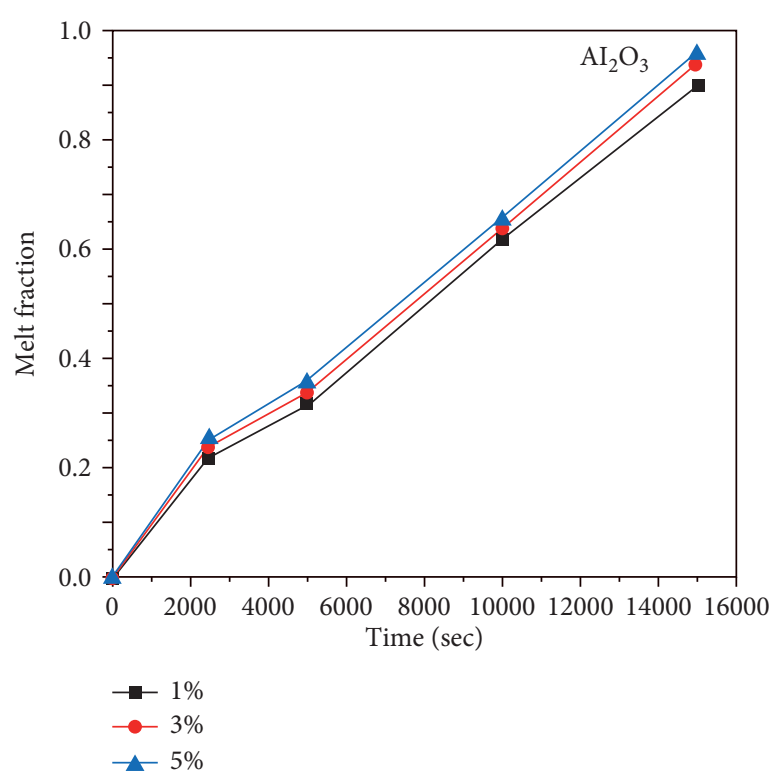

(a)

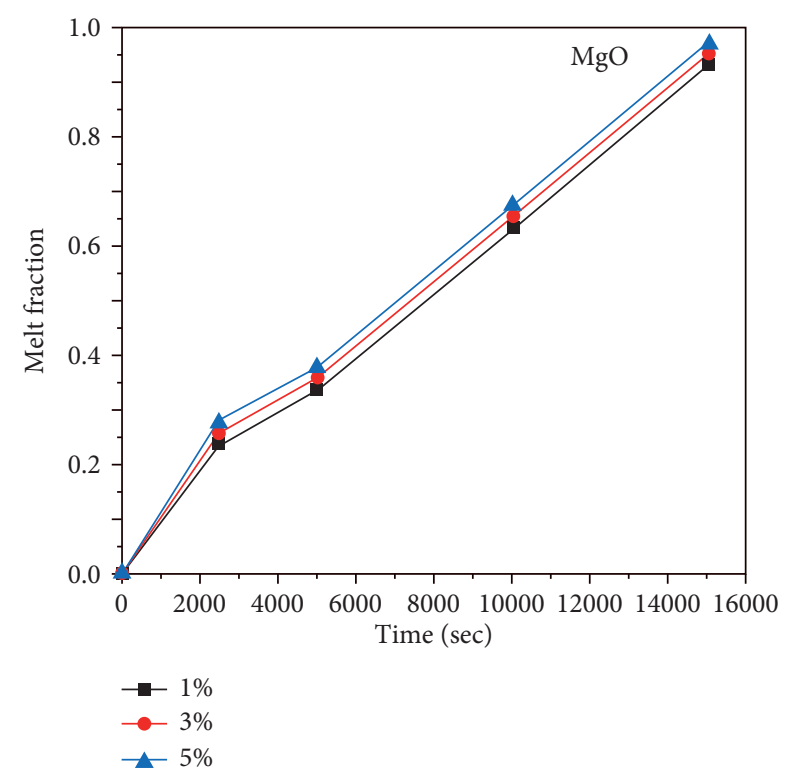

(b)

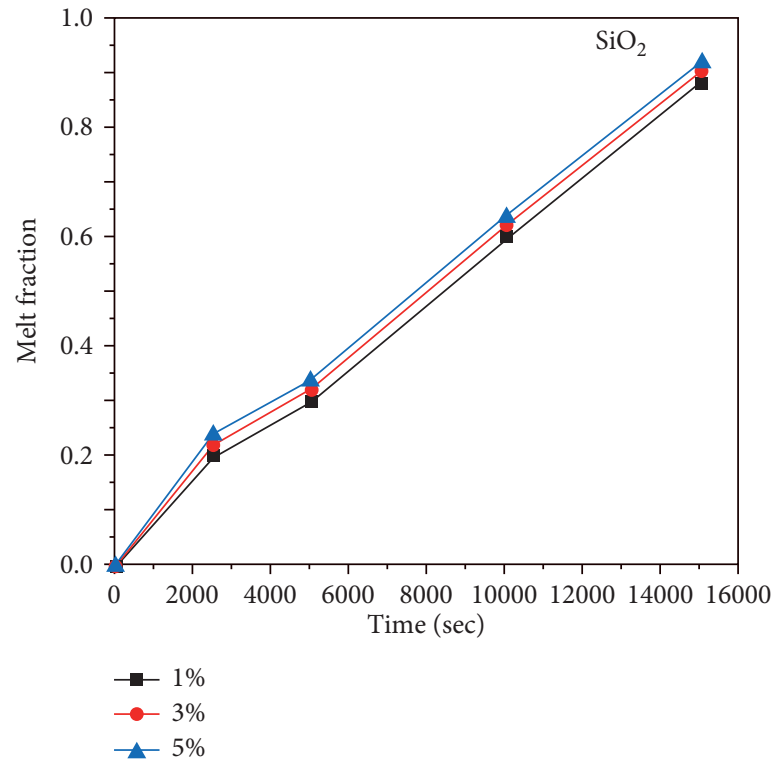

(c)

FIgURe 10: Melt fraction evolution in rec-cir annulus PCM with time and nanoparticle concentration.

Temperature changes of the PCM inside the annulus unit after a different time interval of melting for the different cases as shown in Figure 14. The heat transfer occurred between the hot wall of the annulus and the solid part of the PCM by conduction, which dominated the melting at the early stage of melting and caused a thin layer of liquid to form due to the heat transfer phenomena. As the time progressed, this layer expanded and the liquid fraction increased; the hotter liquid of the PCM was pushed upward to the top of the annulus due to the natural convection effects 


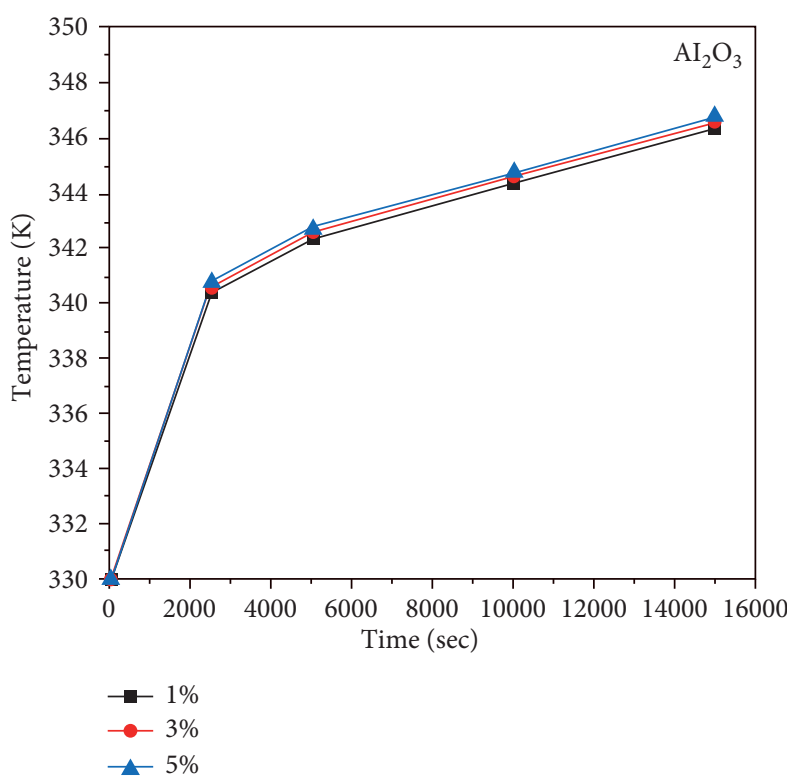

(a)

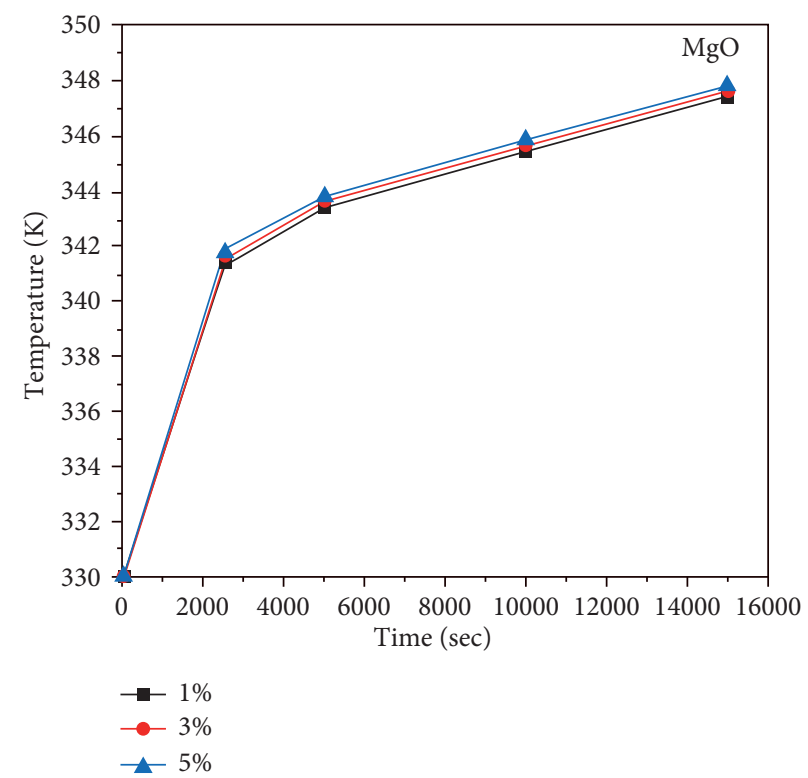

(b)

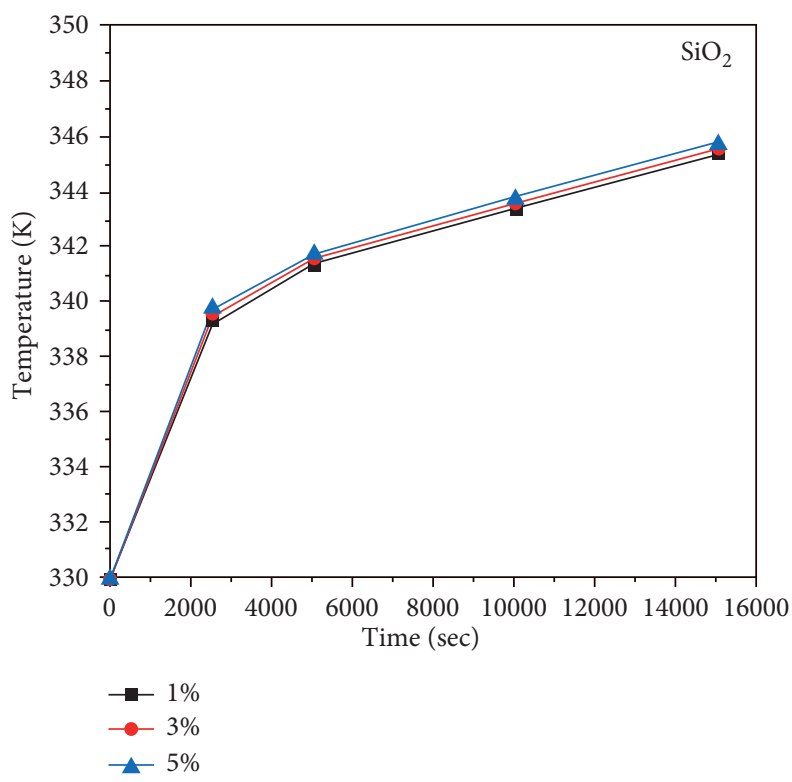

(c)

FIGURE 11: Temperature evolution in rec-cir annulus PCM with time and nanoparticle concentration. 


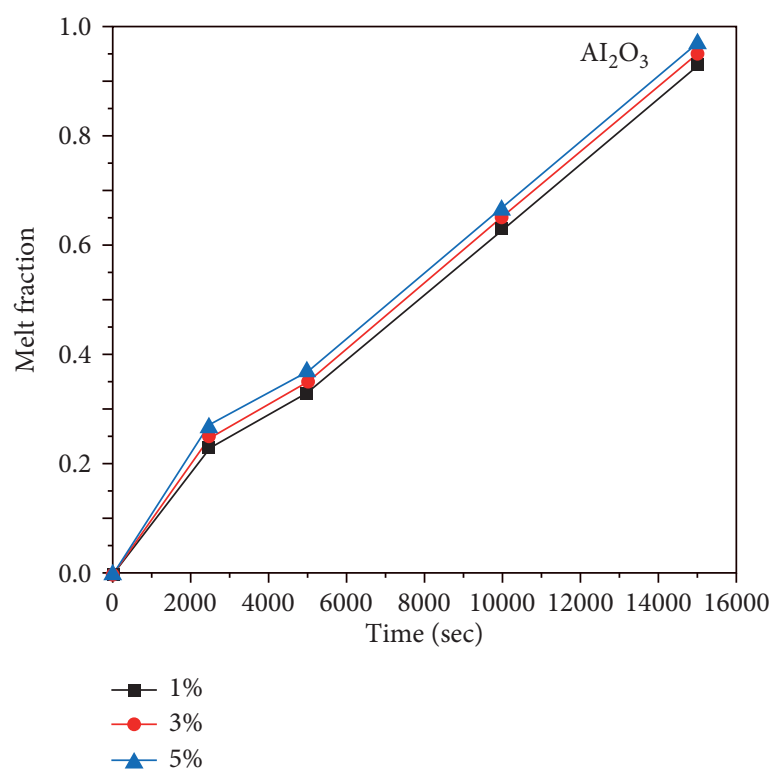

(a)

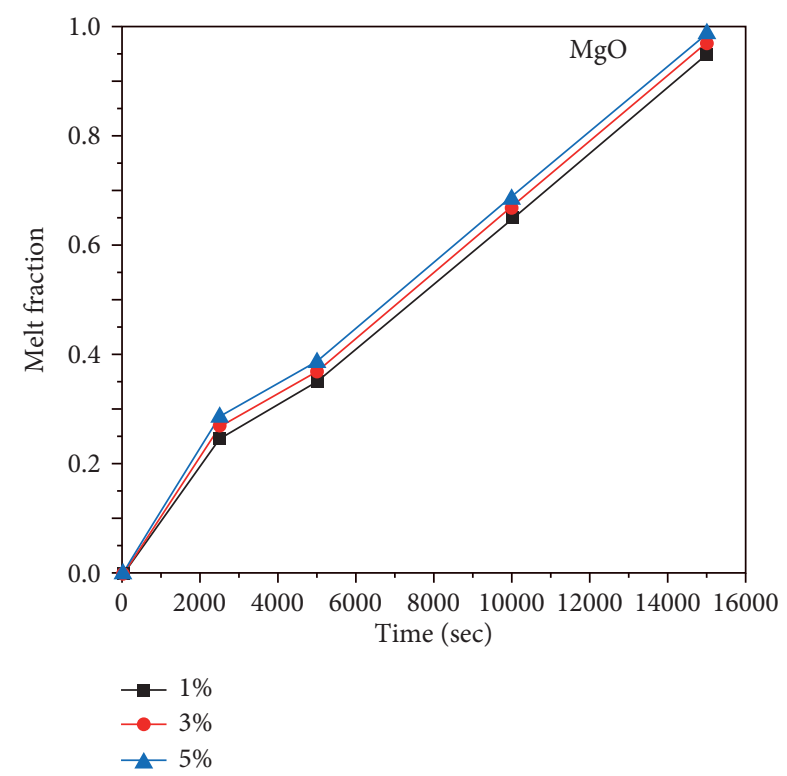

(b)

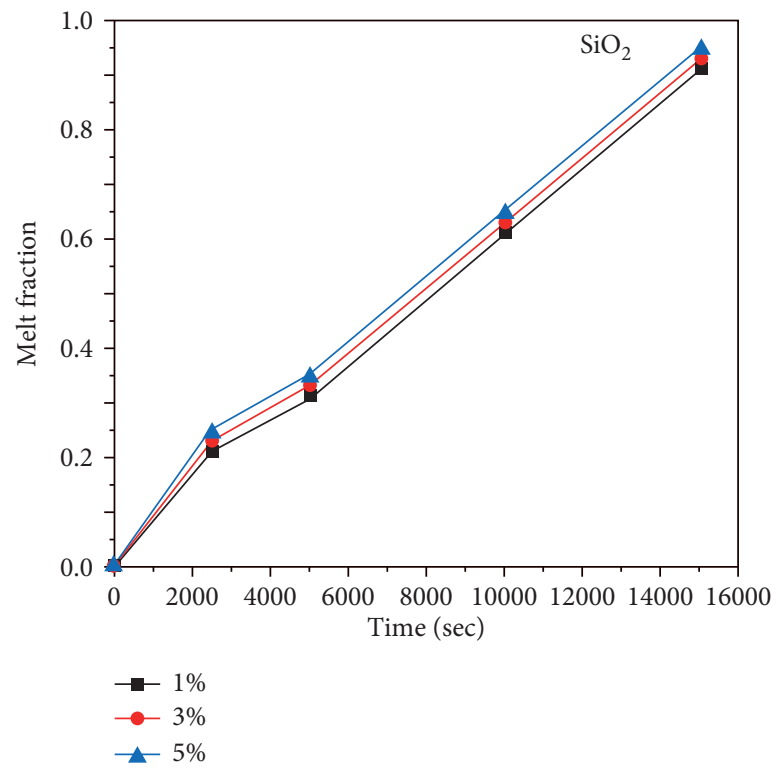

(c)

FIgURe 12: Melt fraction evolution in rec-rec annulus PCM with time and nanoparticle concentration. 


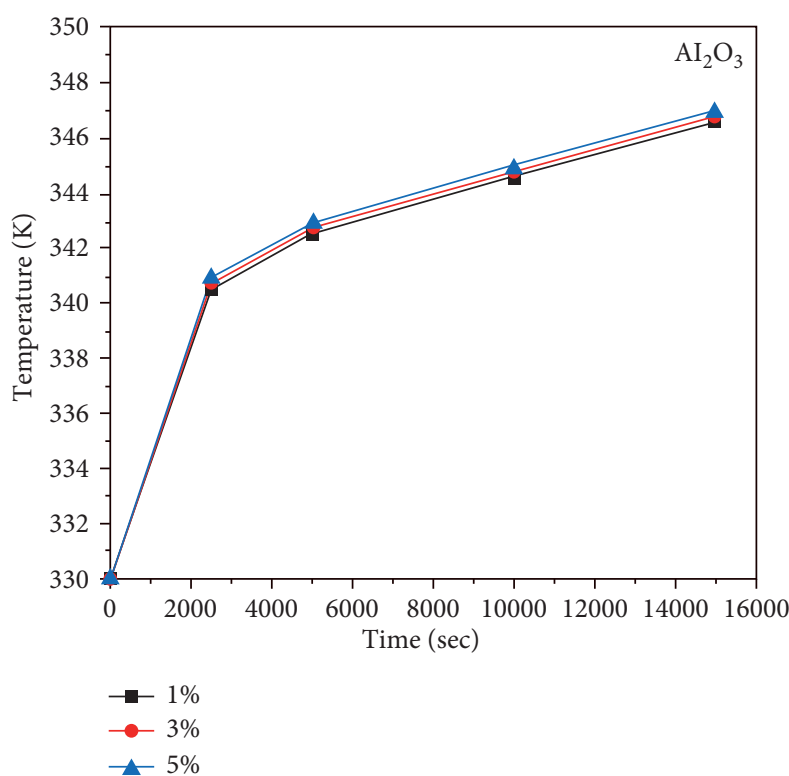

(a)

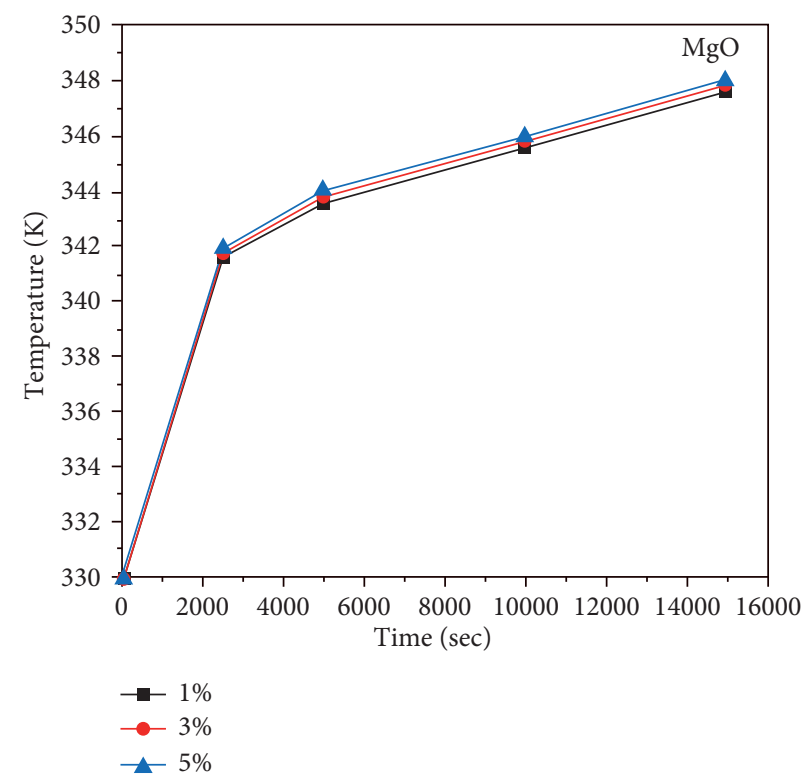

(b)

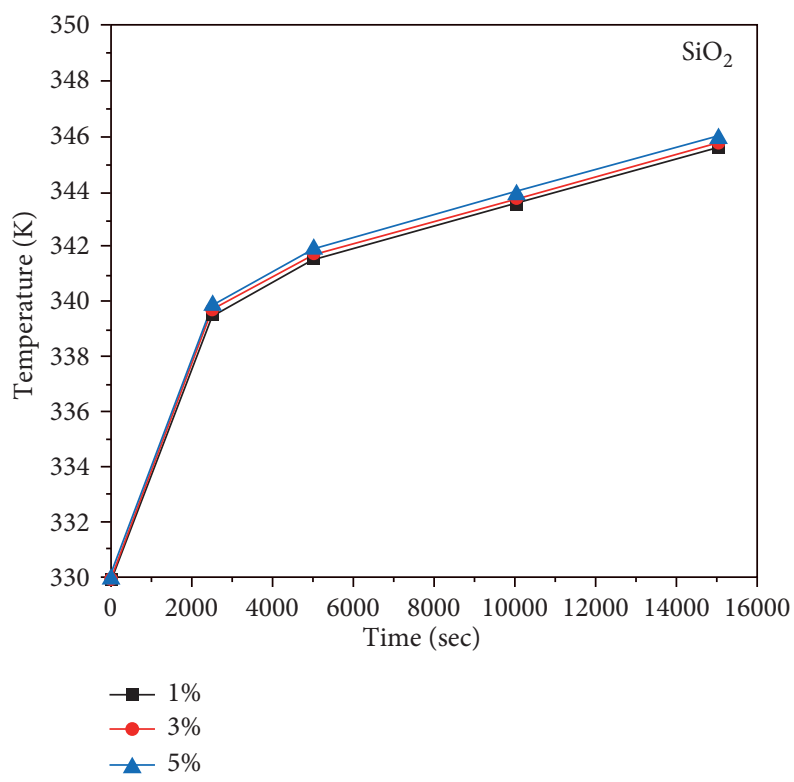

(c)

FIgURE 13: Temperature evolution in rec-rec annulus with PCM time and nanoparticle concentration. 


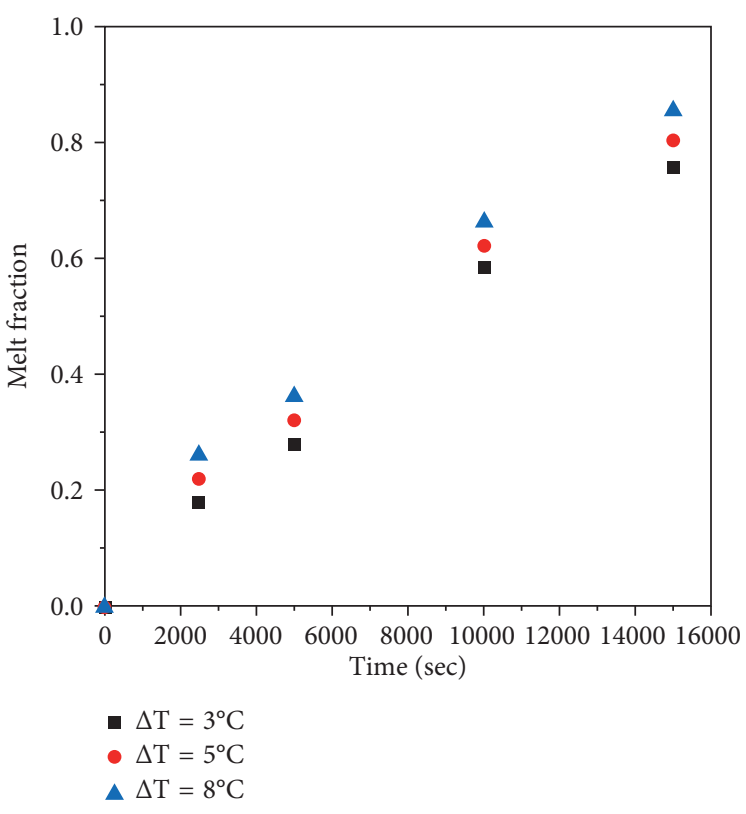

(a)

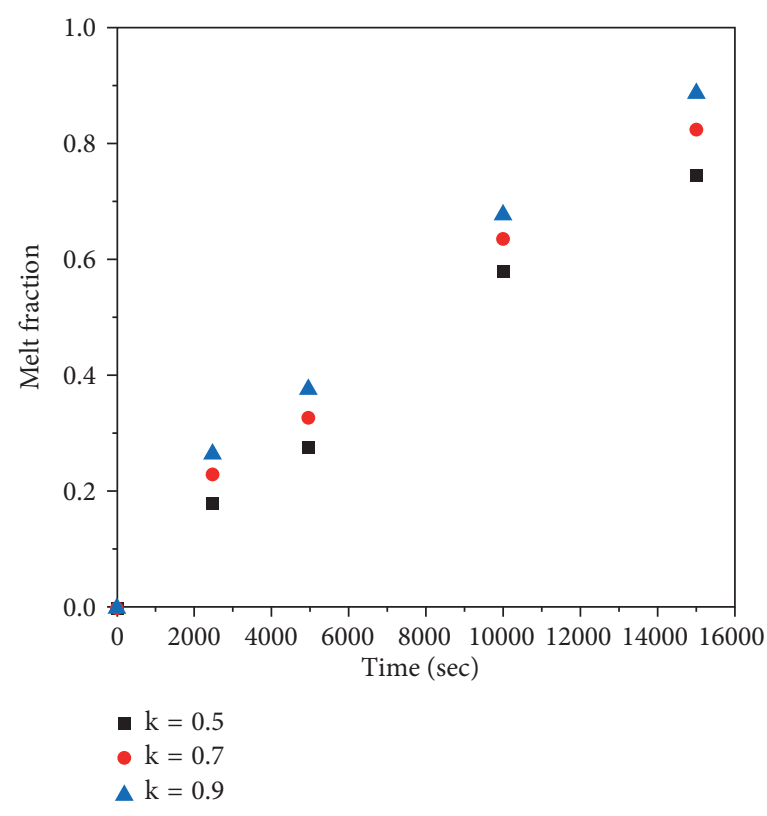

(b)

FIgURE 14: Effect of Stefan number and Rayleigh number on melting time.

driven by buoyancy, whereas the solid part of the PCM was squeezed down to the bottom of the tube by its heavier density.

\section{Conclusions}

The present study focused on the effect of different annulus shape and different nanoparticle concentration on beeswax based PCM and found that

(i) The heat transfer rate and melting efficiency are more in case of rec-rec annulus shape compared with other cases.

(ii) In terms of improving the heat transfer rate and melting efficiency, the composite PCM method is advantageous compared with the pure beeswax.

(iii) Higher $(>5 \%)$ particle concentration is not suggested because the thermal energy storage by the composite PCM reduces with increase of the particle concentration. So, the utilization of less concentration of particle is suggested not only because it maintains high energy storage capacity but also because it delivers better melting efficiency.

(iv) The three investigated metal oxide particles did not demonstrate abundant effect on the melting phenomena. So, the suggestion is to incorporate other kinds of nanoparticles for betterment in the efficiency of the latent heat energy storage system.

(v) It is also recommended for comparable enhancement in heat transfer to adopt a system that encloses the same amount of BW PCM connecting fins [37].

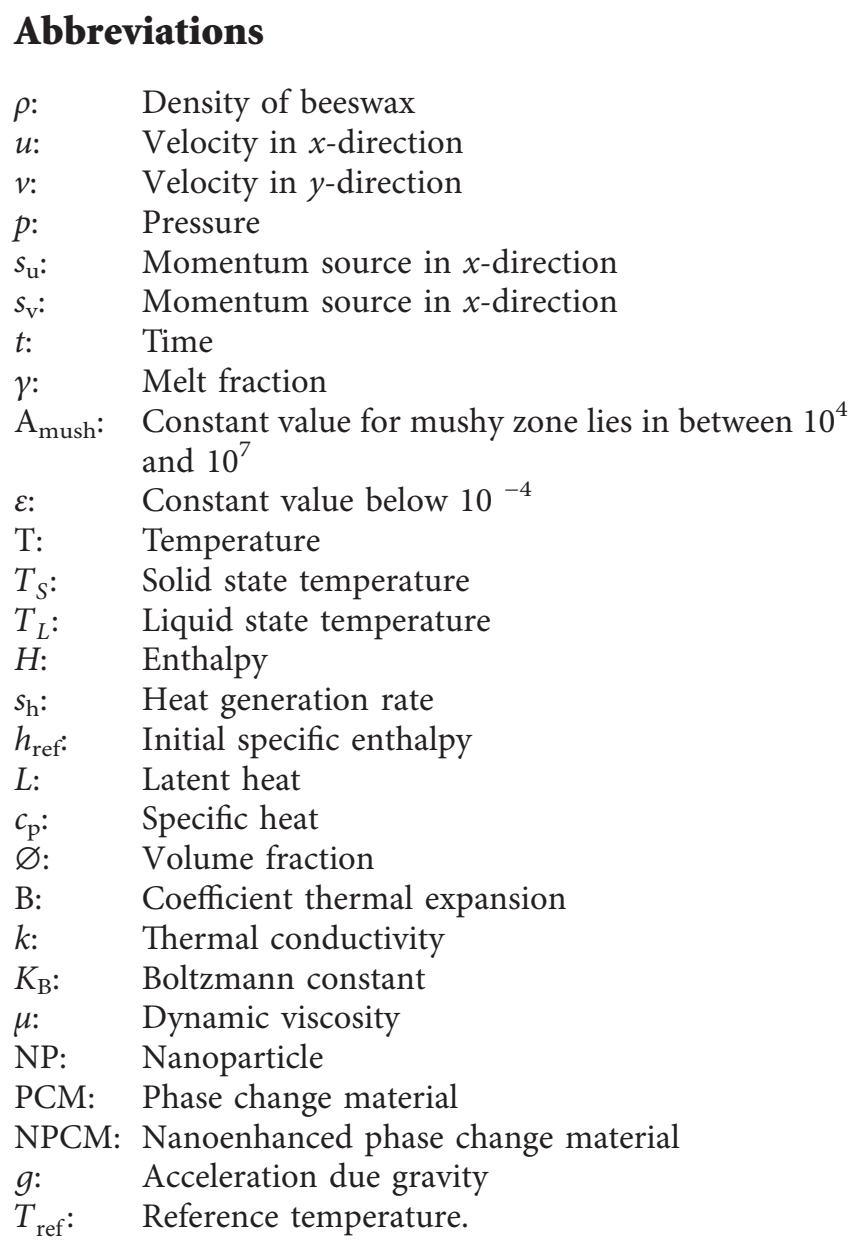




\section{Data Availability}

Supporting data are available in the workstation of computational laboratory of Prof. K M Pandey. However, these data cannot be generalized to be sent to everybody. This is the reason that the results have been provided but the raw data are kept confidential by the authors. The graphs have been generated from the software used and the institute has license of the software used.

\section{Conflicts of Interest}

The authors declare that they have no conflicts of interest.

\section{References}

[1] U. Pelay, L. Luo, Y. Fan, D. Stitou, and M. Rood, "Thermal energy storage systems for concentrated solar power plants," Renewable and Sustainable Energy Reviews, vol. 79, pp. 82100, 2017.

[2] Y. Yuan, N. Zhang, W. Tao, X. Cao, and Y. He, "Fatty acids as phase change materials: a review," Renewable and Sustainable Energy Reviews, vol. 29, pp. 482-498, 2014.

[3] J. M. Mahdi, H. I. Mohammed, P. Talebizadehsardari et al., "Simultaneous and consecutive charging and discharging of a PCM-based domestic air heater with metal foam," Applied Thermal Engineering, vol. 197, Article ID 117408, 2021.

[4] J. M. Mahdi, H. I. Mohammed, and P. Talebizadehsardari, “A new approach for employing multiple PCMs in the passive thermal management of photovoltaic modules," Solar Energy, vol. 222, pp. 160-174, 2021.

[5] P. T. Sardari, D. Grant, D. Giddings, G. S. Walker, and M. Gillott, "Composite metal foam/PCM energy store design for dwelling space air heating," Energy Conversion and Management, vol. 201, Article ID 112151, 2019 Dec 1.

[6] A. Kasaeian, L. bahrami, F. Pourfayaz, E. Khodabandeh, and W.-M. Yan, "Experimental studies on the applications of PCMs and nano-PCMs in buildings: a critical review," Energy and Buildings, vol. 154, pp. 96-112, 2017.

[7] D. K. Mishra, S. Bhowmik, and K. M. Pandey, "Polyethylene glycol based form stable composite phase change material: a review," Journal of Physics Conference Series, vol. 1455, Article ID 12025, 2020.

[8] D. Zhou, C. Y. Zhao, and Y. Tian, "Review on thermal energy storage with phase change materials (PCMs) in building applications," Applied Energy, vol. 92, pp. 593-605, 2012.

[9] K. Pielichowska and K. Pielichowski, "Phase change materials for thermal energy storage," Progress in Materials Science, vol. 65 , pp. 67-123, 2014.

[10] A. Hussein, M. S. Abd-Elhady, M. N. El-Sheikh, and H. T. ElMetwally, "Improving heat transfer through paraffin wax, by using fins and metallic strips," Arabian Journal for Science and Engineering, vol. 43, no. 9, pp. 4433-4441, 2018.

[11] M. Lachheb, K. Mustapha, A. Fethi, B. N. Sassi, F. Magali, and S. Patrik, "Thermal properties measurement and heat storage analysis of paraffin/graphite composite phase change material," Composites, Part B, vol. 66, pp. 518-525, 2014.

[12] K. Du, J. Calautit, Z. Wang, Y. Wu, and H. Liu, "A review of the applications of phase change materials in cooling, heating and power generation in different temperature ranges," $A p$ plied Energy, vol. 220, pp. 242-273, 2018.

[13] D. K. Mishra, S. Bhowmik, and K. M. Pandey, "Analysis on development of beeswax as phase change material for thermal energy storage," Advances in Production and Industrial Engineering, Springer, Singapore, pp. 379-388, 2020.

[14] M. A. Tony and S. A. Mansour, "Sunlight-driven organic phase change material-embedded nanofiller for latent heat solar energy storage," International journal of Environmental Science and Technology, vol. 17, no. 2, pp. 709-720, 2020.

[15] D. K. Mishra, S. Bhowmik, and K. M. Pandey, "Numerical investigation of beeswax based phase change material for thermal management of li-ion battery," Materials Today: Proceeding, vol. 45, pp. 6527-6532, 2021.

[16] S. S. Magendran, F. S. Khan, N. M. Mubarak et al., "Synthesis of organic phase change materials (PCM) for energy storage applications: a review," Nano-Struct. Nano-Objects, vol. 20, Article ID 100399, 2019.

[17] D. K. Mishra, S. Bhowmik, and K. M. Pandey, "Experimental investigations of beeswax based composite phase change material," Recent Advances in Mechanical Engineering, Springer, Singapore, pp. 891-899, 2021.

[18] M. Amin, N. Putra, E. A. Kosasih, E. Prawiro, R. A. Luanto, and T. M. I. Mahlia, "Thermal properties of beeswax/graphene phase change material as energy storage for building applications," Applied Thermal Engineering, vol. 112, pp. 273-280, 2017.

[19] S. Ebadi, S. H. Tasnim, A. A. Aliabadi, and S. Mahmud, "Melting of nano-PCM inside a cylindrical thermal energy storage system: numerical study with experimental verification," Energy Conversion and Management, vol. 166, pp. 241-259, 2018.

[20] M. Sheikholeslami, Z. Li, and A. Shafee, "Lorentz forces effect on NEPCM heat transfer during solidification in a porous energy storage system," International Journal of Heat and Mass Transfer, vol. 127, pp. 665-674, 2018.

[21] C. Y. Zhao, W. Lu, and Y. Tian, "Heat transfer enhancement for thermal energy storage using metal foams embedded within phase change materials (PCMs)," Solar Energy, vol. 84, no. 8, pp. 1402-1412, 2010.

[22] S. S. Sundarram and W. Li, "The effect of pore size and porosity on thermal management performance of phase change material infiltrated microcellular metal foams," $A p$ plied Thermal Engineering, vol. 64, no. 1-2, pp. 147-154, 2014.

[23] M. Iasiello, M. Mameli, S. Filippeschi, and N. Bianco, "Metal foam/PCM melting evolution analysis: orientation and morphology effects," Applied Thermal Engineering, vol. 187, Article ID 116572, 2021.

[24] A. Ghahremannezhad, H. Xu, M. R. Salimpour, P. Wang, and K. Vafai, "Thermal performance analysis of phase change materials (PCMs) embedded in gradient porous metal foams," Applied Thermal Engineering, vol. 179, Article ID 115731, 2020.

[25] N. Bianco, S. Busiello, M. Iasiello, and G. M. Mauro, "Finned heat sinks with phase change materials and metal foams: pareto optimization to address cost and operation time," Applied Thermal Engineering, vol. 197, Article ID 117436, 2021.

[26] Z. A. Qureshi, E. Elnajjar, O. Al-Ketan, R. A. Al-Rub, and S. B. Al-Omari, "Heat transfer performance of a finned metal foam-phase change material (FMF-PCM) system incorporating triply periodic minimal surfaces (TPMS)," International Journal of Heat and Mass Transfer, vol. 170, Article ID 121001, 2021.

[27] M. Gorzin, M. J. Hosseini, M. Rahimi, and R. Bahrampoury, "Nano-enhancement of phase change material in a shell and multi-PCM-tube heat exchanger," Journal of Energy Storage, vol. 22, pp. 88-97, 2019.

[28] S. H. Tasnim, R. Hossain, S. Mahmud, and A. Dutta, "Convection effect on the melting process of nano-PCM 
inside porous enclosure," International Journal of Heat and Mass Transfer, vol. 85, pp. 206-220, 2015.

[29] S. S. Sebti, M. Mastiani, H. Mirzaei, A. Dadvand, S. Kashani, and S. A. Hosseini, "Numerical study of the melting of nanoenhanced phase change material in a square cavity," Journal of Zhejiang University - Science, vol. 14, no. 5, pp. 307-316, 2013.

[30] I. Zarma, M. Ahmed, and S. Ookawara, "Enhancing the performance of concentrator photovoltaic systems using Nanoparticle-phase change material heat sinks," Energy Conversion and Management, vol. 179, pp. 229-242, 2019.

[31] F. Cheng, R. Wen, X. Zhang et al., "Synthesis and characterization of beeswax-tetradecanol-carbon fiber/expanded perlite form-stable composite phase change material for solar energy storage," Composites Part A: Applied Science and Manufacturing, vol. 107, pp. 180-188, 2018.

[32] N. Putra, S. Rawi, M. Amin, E. Kusrini, E. A. Kosasih, and T. M. Mahlia, "Preparation of beeswax/multi-walled carbon nanotubes as novel shape-stable nanocomposite phasechange material for thermal energy storage," Journal of Energy Storage, vol. 21, pp. 32-39, 2019.

[33] N. Putra, E. Prawiro, and M. Amin, "Thermal properties of beeswax/CuO nano phase-change material used for thermal energy storage," Int J Technol, vol. 7, no. 2, pp. 244-253, 2016.

[34] A. Arasu, A. Sasmito, and A. Mujumdar, "Thermal performance enhancement of paraffin wax with $\mathrm{Al} 2 \mathrm{O} 3$ and $\mathrm{CuO}$ nanoparticles-a numerical study," Front Heat Mass Transf, vol. 2, no. 4, 2012.

[35] J. M. Mahdi and E. C. Nsofor, "Solidification of a PCM with nanoparticles in triplex-tube thermal energy storage system," Applied Thermal Engineering, vol. 108, pp. 596-604, 2016.

[36] M. Ghalambaz, S. M. Zadeh, S. A. Mehryan, I. Pop, and D. Wen, "Analysis of melting behavior of PCMs in a cavity subject to a non-uniform magnetic field using a moving grid technique," Applied Mathematical Modelling, vol. 77, pp. 1936-1953, 2020.

[37] M. Ghalambaz and J. Zhang, "Conjugate solid-liquid phase change heat transfer in heatsink filled with phase change material-metal foam," International Journal of Heat and Mass Transfer, vol. 146, Article ID 118832, 2020.

[38] C. J. Ho, Y. C. Liu, M. Ghalambaz, and W. M. Yan, "Forced convection heat transfer of Nano-Encapsulated Phase Change Material (NEPCM) suspension in a mini-channel heatsink," International Journal of Heat and Mass Transfer, vol. 155, Article ID 119858, 2020.

[39] A. S. Mallya and P. Srinivasan, "Numerical simulations and experimental investigations to study the melting behavior of beeswax in a cylindrical container at different angular positions," Journal of Energy Storage, vol. 44, Article ID 103435, 2021.

[40] A. A. Al-Abidi, S. Mat, K. Sopian, M. Y. Sulaiman, and A. T. Mohammad, "Internal and external fin heat transfer enhancement technique for latent heat thermal energy storage in triplex tube heat exchangers," Applied Thermal Engineering, vol. 53, no. 1, pp. 147-156, 2013.

[41] Z. Qian, H. Shen, X. Fang, L. Fan, N. Zhao, and J. Xu, "Phase change materials of paraffin in h-BN porous scaffolds with enhanced thermal conductivity and form stability," Energy and Buildings, vol. 158, pp. 1184-1188, 2018.

[42] S. Harikrishnan, K. Deepak, and S. Kalaiselvam, "Thermal energy storage behavior of composite using hybrid nanomaterials as PCM for solar heating systems," Journal of Thermal Analysis and Calorimetry, vol. 115, no. 2, pp. 1563-1571, 2014.

[43] A. Chibani and S. Merouani, "Acceleration of heat transfer and melting rate of a phase change material by nanoparticles addition at low concentrations," International Journal of Thermophysics, vol. 42, no. 5, pp. 1-16, 2021. 